\title{
Morphogenesis of Streptomyces in Submerged Cultures
}

\section{Dino van Dissel, Dennis Claessen ${ }^{1,2}$, Gilles P. van Wezel ${ }^{1,2}$}

Molecular Biotechnology, Institute Biology Leiden, Leiden University, Leiden, The Netherlands

1'Corresponding authors: e-mail address: d.claessen@biology.leidenuniv.nl; g.wezel@biology.leidenuniv.nl

${ }^{2}$ Shared last author

\section{Contents}

1. Introduction 2

2. Morphogenesis in Submerged Cultures 4

2.1 Hyphal growth 4

2.2 Submerged sporulation 6

2.3 A special case: Streptomyces L-forms 8

3. Molecular Control of Liquid-Culture Morphogenesis 9

3.1 The tip-organizing center and the cytoskeleton 9

3.2 Extracellular polymers and pellet morphology 12

3.3 Proteins that control liquid-culture morphogenesis 13

$\begin{array}{ll}3.4 \text { Surface modification of Streptomyces spores } & 15\end{array}$

4. The SsgA-Like Proteins 16

4.1 SsgA-like proteins and morphotaxonomy of actinomycetes 16

4.2 How does SsgA control hyphal morphogenesis? 18

4.3 SsgA and SsgB control the localization of FtsZ 19

5. Environmental and Reactor Conditions 20

$\begin{array}{ll}5.1 \text { Culture heterogeneity } & 20\end{array}$

$\begin{array}{ll}5.2 \text { Nutrients and morphology } & 21\end{array}$

$\begin{array}{ll}5.3 \text { Fragmentation } & 22\end{array}$

5.4 Relationship between agitation, oxygenation, morphology, and productivity 24

6. Morphology and Antibiotic Production 25

6.1 Impact of morphology on antibiotic production 25

6.2 PCD and antibiotic production 27

7. Outlook: The Correlation Between Morphology and Production 29

Acknowledgments $\quad 32$

References $\quad 32$

\begin{abstract}
Members of the genus Streptomyces are mycelial bacteria that undergo a complex multicellular life cycle and propagate via sporulation. Streptomycetes are important industrial microorganisms, as they produce a plethora of medically relevant natural products, including the majority of clinically important antibiotics, as well as a wide range of
\end{abstract}


enzymes with industrial application. While development of Streptomyces in surfacegrown cultures is well studied, relatively little is known of the parameters that determine morphogenesis in submerged cultures. Here, growth is characterized by the formation of mycelial networks and pellets. From the perspective of industrial fermentations, such mycelial growth is unattractive, as it is associated with slow growth, heterogeneous cultures, and high viscosity. Here, we review the current insights into the genetic and environmental factors that determine mycelial growth and morphology in liquid-grown cultures. The genetic factors include cell-matrix proteins and extracellular polymers, morphoproteins with specific roles in liquid-culture morphogenesis, with the SsgA-like proteins as well-studied examples, and programmed cell death. Environmental factors refer in particular to those dictated by process engineering, such as growth media and reactor set-up. These insights are then integrated to provide perspectives as to how this knowledge can be applied to improve streptomycetes for industrial applications.

\section{INTRODUCTION}

Streptomycetes are filamentous bacteria that belong to the phylum of actinobacteria. These medically and industrially highly relevant microorganisms are producers of over half of the antibiotics used in the clinic today as well as of a plethora of other natural products, such as anticancer, immunosuppressive, antifungal, and anthelmintic agents (Baltz, 2007, 2008; Hopwood, 2007; Olano, Méndez, \& Salas, 2009). Furthermore, streptomycetes are saprophytic bacteria that grow on almost any natural polymer, and as such are a rich source of industrial enzymes (Bhosale, Rao, \& Deshpande, 1996; Tokiwa \& Calabia, 2004; Vrancken \& Anné, 2009; Yikmis \& Steinbüchel, 2012). Unlike most other bacteria, streptomycetes are nonplanktonic and grow as a mycelium consisting of a network of closely interwoven hyphae. Exponential growth is thereby achieved by a combination of tip extension and branching. The multigenomic hyphae are divided by occasional crosswalls, which make Streptomyces a rare example of a multicellular prokaryote (Claessen, Rozen, Kuipers, Søgaard-Andersen, \& van Wezel, 2014). When nutrient availability becomes limiting, streptomycetes initiate a complex developmental program, which leads to morphological and chemical differentiation (Chater \& Losick, 1997; Flärdh \& Buttner, 2009). At this stage, aerial hyphae are formed that are coated with waterrepellent proteins to allow them to break through the aqueous soil surface and grow into the air (Claessen, de Jong, Dijkhuizen, \& Wösten, 2006; Wösten \& Willey, 2000). Eventually, the aerial hyphae differentiate into chains of unigenomic spores, following a spectacular cell division process 
whereby some 100 septa are produced in a very short time span (Jakimowicz \& van Wezel, 2012; Schwedock, McCormick, Angert, Nodwell, \& Losick, 1997). Genes that are involved in the onset of aerial mycelium formation are designated bald (bld) genes, characterized by the bald appearance of mutants due to their failure to produce the fluffy aerial hyphae (Merrick, 1976), and those that are essential for the formation of gray-pigmented spores are called white $(w h i)$ genes, characterized by the white appearance of mutants due to the lack of the WhiE spore pigment (Chater, 1972). It is important to note that most of the developmental regulators function by controlling transcription or translation. In this review, we primarily focus on the genes that control morphogenesis in submerged culture. For detailed information on the genes that control aerial hyphae formation and sporulation in surface-grown cultures, we refer to excellent reviews elsewhere (Chater \& Losick, 1997; Flärdh \& Buttner, 2009; Kelemen \& Buttner, 1998).

The timing of antibiotic production is tightly controlled with the life cycle, and many antibiotics are produced at a time correlated to the onset of morphological differentiation (Bibb, 2005; Liu, Chater, Chandra, Niu, \& Tan, 2013; van Wezel \& McDowall, 2011). Mutants that are blocked in development (so-called bld mutants) therefore typically fail to produce antibiotics (Bibb, 2005). The onset of development and antibiotic production coincides with the autolytic dismantling of the vegetative mycelium, necessary to provide nutrients as building blocks for the aerial mycelium, in a process strongly resembling programmed cell death (PCD) (Fernandez \& Sanchez, 2002; Manteca, Mäder, Connolly, \& Sanchez, 2006).

Industry-level production of secondary metabolites and enzymes occurs in bioreactors, and industrial exploitation of streptomycetes is hampered by the formation of large mycelial networks or clumps, which is unattractive from the perspective of process engineering (Braun \& Vecht-Lifshitz, 1991; Hodgson, 2000; van Wezel, McKenzie, \& Nodwell, 2009). Compared to fermentations with unicellular microorganisms such as Saccharomyces cerevisiae, Escherichia coli, or Bacillus subtilis, the more complex morphology of streptomycetes puts constraints on the ability to maximize product yields (Wucherpfennig, Kiep, Driouch, Wittmann, \& Krull, 2010). Entanglement of mycelia increases the viscosity of the broth, which lowers the transfer rates of nutrients and gases, and because many strains have the tendency to aggregate into pellets a part of the biomass might be shielded from the supply of nutrients altogether. To further complicate matters, optimal productivity is 
tied to morphology in a product-specific manner, meaning that often less favored conditions have to be accepted for optimal productivity (Anné, Vrancken, Van Mellaert, Van Impe, \& Bernaerts, 2014; Martin \& Bushell, 1996; van Wezel et al., 2006; Wardell, Stocks, Thomas, \& Bushell, 2002).

We are only beginning to unravel the mechanisms that control morphogenesis of streptomycetes, and this is particularly true for mycelial growth in submerged cultures. At the same time, understanding the correlation between morphogenesis and productivity is of critical importance for the exploitation of streptomycetes in the industrial domain. In this review, we present an overview of the current literature on the morphogenesis of streptomycetes in liquid-grown cultures and look at how this may be translated to better match morphology and productivity during industrial fermentations.

\section{MORPHOGENESIS IN SUBMERGED CULTURES}

\subsection{Hyphal growth}

Active growth of streptomycetes typically starts with spore germination. The spore is not only a means for dispersal but also serves as a way to survive a period of adverse environmental conditions. Once the conditions become favorable for growth, spores typically establish two germ tubes at the polar sides, which grow out to become young vegetative hyphae. The molecular steps responsible for the emergence of germ tubes have not yet been identified, and surprisingly little is known about this germination process. One reason may be that it is difficult to differentiate between early signaling events for the onset of germination and essential metabolic and housekeeping activities that relate to early growth. Spore germination is controlled by the cyclic AMP receptor protein Crp (Derouaux et al., 2004; Piette et al., 2005), but Crp also controls antibiotic production (Gao, Hindra, Mulder, Yin, \& Elliot, 2012). A major consequence of the absence of Crp was the production of a very thick spore wall, which was identified as a likely cause for the germination delay (Piette et al., 2005). The correlation between cell wall hydrolysis and the speed of germination was further supported by the delayed germination in the absence of the cell wall hydrolase RpfA (Haiser, Yousef, \& Elliot, 2009). Another cell wall-associated protein that relates to germination is NepA, originally identified as a protein that localizes to the "subapical stem," which connects vegetative with aerial hyphae during early 
development (Dalton, Thibessard, Hunter, \& Kelemen, 2007). Deletion of nер $A$ results in altered germination, which in particular occurs in a more synchronized manner (de Jong, Manteca, et al., 2009).

After germination, the hyphae grow out to form a branched network of hyphae, the vegetative mycelium. Studies in streptomycetes with compounds that are incorporated into newly synthesized peptidoglycan, such as labeled vancomycin or $\mathrm{N}$-acetylglucosamine, revealed that peptidoglycan synthesis primarily occurs at hyphal tips and - therefore by definition-also at emerging branches (Daniel \& Errington, 2003; Gray, Gooday, \& Prosser, 1990). Penicillins particularly target apical sites of the hyphae, and less the lateral walls, and the latter may therefore be regarded as a relatively inert murein. During normal growth of streptomycetes, crosswalls are formed in the hyphae, which do not lead to cell fission, thus resulting in long multinucleoid compartments (Chater \& Losick, 1997; Flärdh \& van Wezel, 2003; Jakimowicz \& van Wezel, 2012). Branches are formed at sites behind the tip, and frequently but not always adjacent to crosswalls, leading to the establishment of new cell poles, and the combination of apical growth and branching ensures exponential growth (Flärdh, Richards, Hempel, Howard, \& Buttner, 2012).

Subsequent growth and morphology of the mycelial mass is in part strain-dependent. Three types of morphologies are generally distinguished in liquid-grown cultures: (1) freely dispersed mycelia, which predominantly behave like single cells with high mass transfer properties; (2) open mycelial networks, also often called mycelial mats, which generally have good mass transfer characteristics, but increase the viscosity of the media; and (3) pellets that do not increase the viscosity significantly, but often contain a nutrient-deprived center (Paul \& Thomas, 1998; Fig. 1.1). The wide range of morphological phenotypes, which often coexist in the reactor, is due to the large number of variables that influence the ability of the mycelia to grow, branch, aggregate, and fragment (see Chapter 5). The dominant type is genetically determined and differs considerably between strains. For instance, Streptomyces venezuelae typically forms highly dispersed mycelia and sporulates in liquid cultures, Streptomyces clavuligerus forms mycelial mats, while Streptomyces coelicolor mostly forms large and dense pellets (Bewick, Williams, \& Veltkamp, 1976; van Wezel et al., 2006). These differences already reveal that general predictions are difficult to make, although some genetic determinants influence morphology regardless of the strain (see below). 

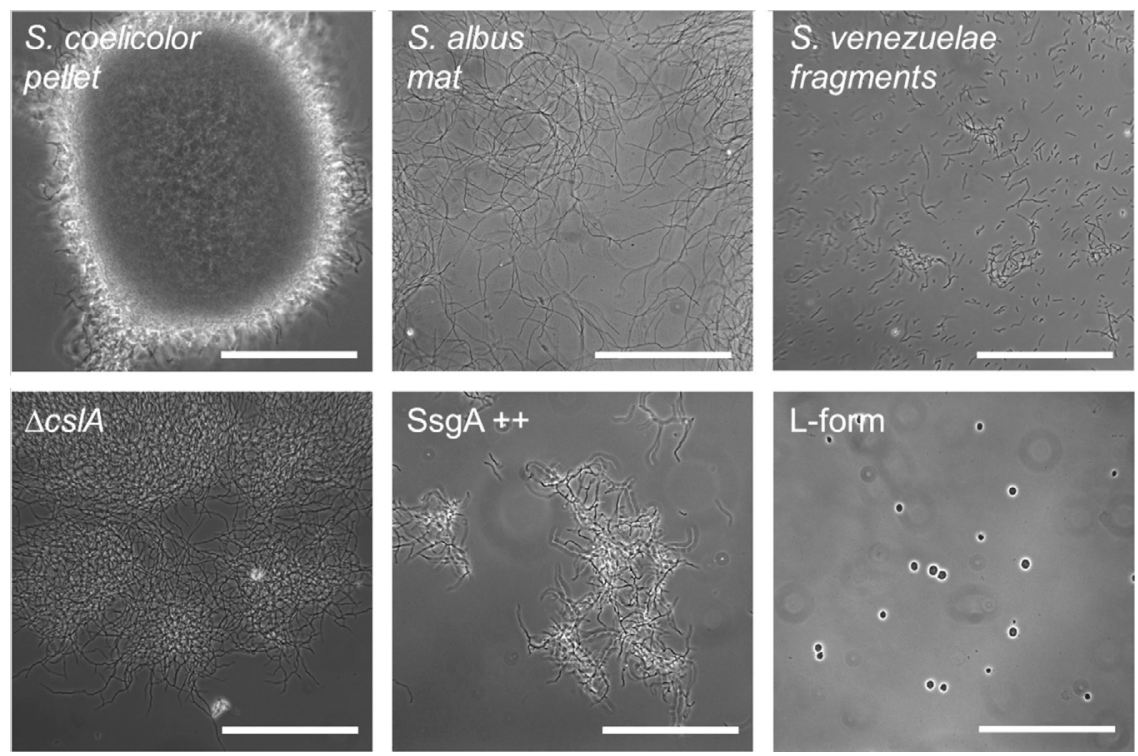

Figure 1.1 Distinct morphologies of Streptomyces species in submerged cultures. Top row: Streptomyces strains representing different morphologies, namely pellets (S. coelicolor), mycelial mats (S. albus), and fragments (S. venezuelae). Bottom row: changes in morphology due to genetic factors. Images show cs/A null mutant (left), SsgA-overexpressing strains (middle) of S. coelicolor, and L-form cells (right) derived from S. viridifaciens. Scale bar, $100 \mu \mathrm{m}$.

\subsection{Submerged sporulation}

Whereas major differences in mycelial architecture are observed between different streptomycetes, further complexity is caused by the capacity of some strains to form spores in liquid environments. The first report of submerged sporulation was made as early as in 1947 (Erikson, 1947). However, in 1983 Kendrick and Ensign provided a groundbreaking study on the morphology and on sporulation of Streptomyces griseus B-2682 in submerged culture (Kendrick \& Ensign, 1983). This led to the identification of several streptomycetes that produce submerged spores, including Streptomyces granaticolor, S. griseus, Streptomyces roseosporus, and S. venezuelae (Daza, Martín, Dominguez, \& Gil, 1989; Glazebrook, Doull, Stuttard, \& Vining, 1990; Kendrick \& Ensign, 1983). These can be further subdivided into streptomycetes that only sporulate in nutrient-limiting media, such as S. griseus (Kendrick \& Ensign, 1983), and those that produce submerged spores in nearly all media, such as S. venezuelae (Glazebrook et al., 1990). Although until recently it was believed that the ability to produce spores 
in liquid cultures was something like a rarity, the possibility cannot be ruled out that in principle all streptomycetes can do so under specific conditions; indeed, a recent survey revealed that submerged sporulation is likely much more widespread than originally anticipated, with half of a random selection of over 50 streptomycetes sporulating in submerged culture at least under some growth conditions (Girard et al., 2013). Interestingly, addition of high concentrations of calcium to liquid-grown cultures of $S$. coelicolor and Streptomyces lividans induces the occasional formation of spore-like compartments. Since phosphate starvation is an important trigger for submerged sporulation, this calcium effect was explained by the reduction of the phosphate pool (Daza et al., 1989; Glazebrook et al., 1990; Kendrick \& Ensign, 1983), although further analysis is required to corroborate this.

There is a clear transition in the vegetative hyphae prior to submerged sporulation: the hyphae thicken, and widened club-like structures or "preconidia" are produced at the apical sites of the hyphae (Biró, Békési, Vitális, \& Szabó, 1980; Rueda, Miguélez, Hardisson, \& Manzanal, 2001a). Comparison of thin sections of aerial and submerged spores by transmission electron microscopy (TEM) showed that the cell walls of surface-grown spores are thicker than those of submerged spores, with a width of approximately $40 \mathrm{~nm}$ and $25 \mathrm{~nm}$, respectively (Kendrick \& Ensign, 1983). However, aerial and submerged sporogenic hyphae of Streptomyces braziliensis by TEM show strong similarity (Rueda, Miguélez, Hardisson, \& Manzanal, 2001b), with the main difference in the appearance of the sheath around the hyphae, which was thinner and less structured in sporogenic vegetative hyphae, perhaps due to a difference in the rodlet layer (Gebbink, Claessen, Bouma, Dijkhuizen, \& Wösten, 2005).

While sporulation of streptomycetes is typically studied in surface-grown cultures, the study of sporulation in submerged cultures is an attractive alternative for several reasons. First of all, culturing time is much shorter, and synchronous sporulation can be more readily achieved. Sporulation of S. griseus is induced by transferring the strain from rich to nutrient-limited media, whereby sporogenic hyphae become evident within a few hours and then continue to elongate until septation occurs at approximately $10 \mathrm{~h}$, with spores maturing over a subsequent period of 10-12 h (Kwak \& Kendrick, 1996).

In addition to the advantage of synchronization of cultures, submerged development also readily facilitates global expression profiling by systems biology approaches like transcriptome, proteome, or metabolome analysis. This is exemplified by recent studies on developmental mutants in S. venezuelae (Bibb, Domonkos, Chandra, \& Buttner, 2012; Bush, Bibb, Chandra, Findlay, \& Buttner, 2013). Buttner and colleagues are currently 
developing S. venezuelae as model system for morphological differentiation for its ability to readily sporulate in both minimal and rich liquid media, and developmental (bld, whi) mutants that were studied previously in S. coelicolor are being recreated in this interesting background to facilitate "-omics" approaches (M. Buttner \& M. Bibb, pers. comm.). Submerged sporulation also allows discriminating between genes involved in the control of aerial hyphae formation and those required for sporulation-specific cell division. After all, the former is not relevant in submerged cultures, and presumably genes required for erection of aerial hyphae should not interfere with the ability to initiate sporulation-specific cell division, while the cell division process itself is likely very similar during submerged and solid culture sporulation. Thus, submerged sporulation should be a particularly good model system for studies on developmental cell division.

\subsection{A special case: Streptomyces L-forms}

Mycelial growth is a hallmark feature of streptomycetes. Production of secondary metabolites, such as antibiotics or antitumor agents, is often linked to the inherent capacity to form mycelial pellets. However, streptomycetes can also be forced to produce single cells. Treatment of mycelia with lysozyme results in the formation of protoplasts, which are identical-sized spherical cells without a cell wall used for cell fusion and plasmid transformation (Bibb, Ward, \& Hopwood, 1978; Hopwood, Wright, Bibb, \& Cohen, 1977). While protoplasts cannot propagate, streptomycetes can also form so-called L-forms (Innes \& Allan, 2001). Selection of L-forms occurs by growth in the presence of lysozyme, which degrades the peptidoglycan, and penicillin, which inhibits de novo peptidoglycan synthesis. Subsequent cultivations in osmotically balanced media can lead to the acquisition of mutations that allow these cells to propagate without their cell wall, even in the absence of the inducing agents (i.e., penicillin and lysozyme; Innes \& Allan, 2001; Leaver, Dominguez-Cuevas, Coxhead, Daniel, \& Errington, 2009; Mercier, Kawai, \& Errington, 2013; Errington, 2013). L-forms have been shown to associate with plants acting as biocontrol agents (Amijee, Allans, Waterhouse, Glover, \& Paton, 1992; Innes \& Allan, 2001). The absence of a cell wall allows these pleomorphic cells to invade spaces that would otherwise be inaccessible, such as the extracellular space within plant tissue or even inside plant cells (Paton \& Innes, 1991). Biocontrol activity was shown for Pseudomonas and Bacillus species (Amijee et al., 1992; Walker, Ferguson, Booth, \& Allan, 2002; Waterhouse, 
Buhariwalla, Bourn, Rattray, \& Glover, 1996), but could also be true for streptomycetes, which naturally produce a large arsenal of antifungal and antimicrobial compounds (Hopwood, 2007).

L-forms have been generated in a wide range of unrelated bacterial species, including, among others, Escherichia coli (Glover, Yang, \& Zhang, 2009), B. subtilis (Leaver et al., 2009), and Listeria monocytogenes (Dell'Era et al., 2009), and also in several Streptomyces species, including Streptomyces hygroscopicus, S. griseus, Streptomyces levoris, and Streptomyces viridifaciens (Gumpert, 1982, 1983; Innes \& Allan, 2001; Fig. 1.1). Note that "S. viridifaciens" was recently proposed to belong to the genus Kitasatospora (Girard et al., 2014) L-form growth is largely driven by changes in the cell surface area to volume ratio of these cells and is characterized by blebbing, tubulation, vesiculation, and fission (Errington, 2013; Mercier et al., 2013). Interestingly, division of phospholipid vesicles, which to some extent resemble empty L-forms, could merely be driven by changes in lipid composition (Peterlin, Arrigler, Kogej, Svetina, \& Walde, 2009). Also, cell division of L-forms is stimulated by increased fatty acid synthesis (Mercier et al., 2013) and does not require the canonical cell division machinery (Leaver et al., 2009). As such, L-form proliferation could mimic how primordial cells propagated before the cell wall was invented.

The production of secondary metabolites by streptomycetes is often linked to the complex pattern of morphological development (van Wezel \& McDowall, 2011). Surprisingly, stable L-forms of S. viridifaciens were still able to produce tetracycline, in addition to another uncharacterized green-pigmented metabolite (Innes \& Allan, 2001). However, compared to the parental form, the yields were relatively low. Nevertheless, the capacity of L-forms to produce secondary metabolites including antibiotics highlights their potential use as biocontrol agents.

\section{MOLECULAR CONTROL OF LIQUID-CULTURE
MORPHOGENESIS}

\subsection{The tip-organizing center and the cytoskeleton}

During apical growth, DivIVA localizes close to the growing tip and its pivotal role in the control of apical growth is highlighted by the fact that it is essential for growth, while its overexpression leads to drastic changes in hyphal morphology including hyper-branching (Flärdh et al., 2012; Hempel et al., 2012). In B. subtilis, DivIVA controls septum-site 
determination by interacting with the MinCD cell division inhibitor complex (Edwards \& Errington, 1997). However, streptomycetes lack a Min system, and DivIVA has instead taken up a (yet not fully understood) role in apical growth.

DivIVA is part of a larger complex of proteins that collectively have been dubbed tip-organizing center (TIPOC; Fig. 1.2; Holmes et al., 2013). In recent years, several proteins and protein complexes have been identified that play a role in tip growth and DNA replication. These include the Streptomyces cytoskeletal element Scy (Holmes et al., 2013), the twin-arginine transport (Tat) secretion system (Willemse et al., 2012), the cell wall remodeling protein SsgA (Noens et al., 2007), and the cellulose synthase-like protein CslA (Xu, Chater, Deng, \& Tao, 2008). Furthermore, new chromosomes are also replicated close to but distinctly away from the tip in so-called replisomes (Wolánski et al., 2011). The TIPOC likely ensures that all apical processes, such as DNA replication and cell wall synthesis, are carried out in

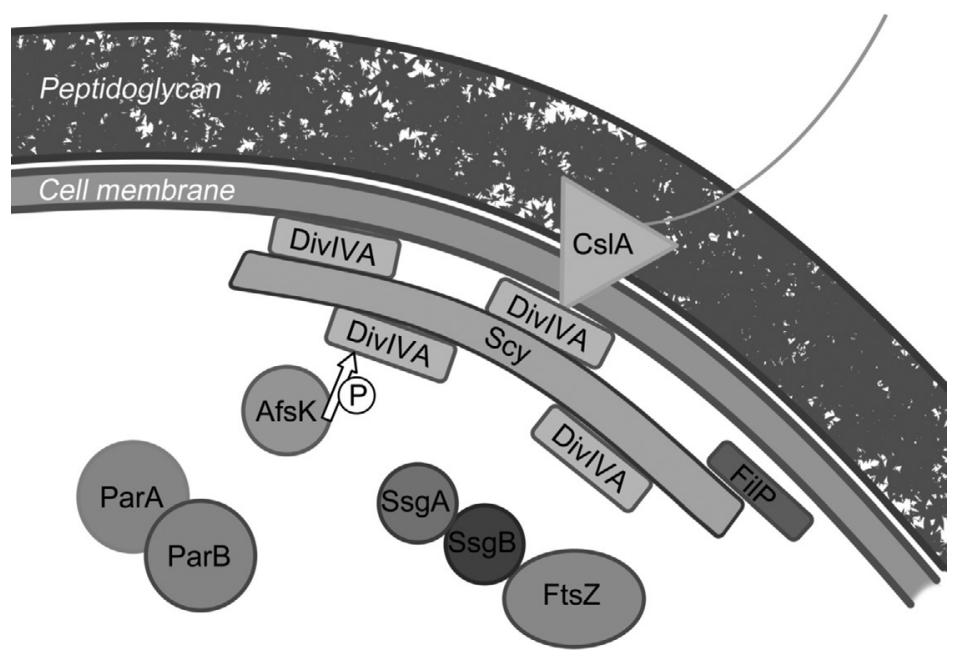

Figure 1.2 Components of the tip-organizing center (TIPOC) of S. coelicolor. The TIPOC is a multiprotein complex that coordinates tip growth, cell wall synthesis, DNA replication and segregation, and cell division. DivIVA is required for peptidoglycan synthesis and interacts directly with the cytoskeletal protein Scy. The latter assists in assembly of the complex. Other members include the cellulose synthase-like protein CsIA, the cytoskeletal element FilP and SsgA, which controls processes requiring cell wall remodeling. The TIPOC interacts with the proteins involved in chromosome segregation (ParA and ParB) and probably with those involved in cell division (SsgA, SsgB, and FtsZ). AfsK negatively controls the activity of DivIVA by phosphorylation. For further details and references, see the text. Adapted from Holmes et al. (2013). 
coordinated fashion (Ditkowski et al., 2013; Fuchino et al., 2013) and that DNA is not damaged by the cell wall synthetic machinery (K. Celler \& $\mathrm{GPvW}$, unpublished data). The extracellular cellulose-like polymer synthesized by CslA might form an additional protective layer at the outside of the hyphal tips, thereby preventing cell damage (Chater, Biro, Lee, Palmer, \& Schrempf, 2010).

Recent evidence indicates that DivIVA is phosphorylated by the Ser/ Thr protein kinase AfsK (Hempel et al., 2012). The C-terminal part of DivIVA has multiple sites for phosphorylation, and the level of phosphorylation increases dramatically when cell wall synthesis is arrested (Hempel et al., 2012). Increased phosphorylation coincided with the disappearance of DivIVA from the hyphal tips, followed by the emergence of new lateral branches. Under normal growth conditions, branches are formed by a so-called tip-splitting mechanism, in which new foci of DivIVA originate from existing foci (Richards, Hempel, Flärdh, Buttner, \& Howard, 2012). Consistent with the observation that DivIVA is required for apical growth, it is recruited to branch sites to allow the start of apical growth.

The cytoskeleton of streptomycetes is highly complex, with likely over 10 different cytostructural proteins (recently reviewed in Celler, Koning, Koster, \& van Wezel, 2013). The Scy protein acts in close collaboration with DivIVA in establishing growth polarity (Holmes et al., 2013). In contrast to $\operatorname{divIVA}, s c y$ can be deleted, which has a pronounced effect of hyphal morphology. Notably, in the absence of Scy, hyphal tips were often branching, leading to a tip-splitting phenotype and aberrant hyphal geometry. The Scy protein is a large 1326-amino acid (a) protein with a high propensity to form coiled-coil structures. In vitro experiments indicated that this protein forms long filaments, which potentially act as a scaffold for the assembly of the TIPOC. Indeed, Scy not only interacts with DivIVA but also with the chromosome-partitioning protein ParA (Ditkowski et al., 2013) and with the intermediate filament-like protein FilP, encoded by a gene immediately downstream of scy (Bagchi, Tomenius, Belova, \& Ausmees, 2008; Holmes et al., 2013). FilP also interacts with DivIVA, which indicates that these three proteins together form a large polar assembly that likely plays a role in the spatial and temporal control of apical growth (Fig. 1.2). Interestingly, during sporulation of B. subtilis, DivIVA interacts with the chromosome segregation machinery, to aid in positioning the oriC region of the chromosome at the cell pole, in preparation for polar division (Thomaides, Freeman, El Karoui, \& Errington, 2001). Considering the polar interaction with ParA, this functionality of DivIVA is retained in streptomycetes. 


\subsection{Extracellular polymers and pellet morphology}

Multicellular structures are typically held together by an extracellular matrix (Branda, Vik, Friedman, \& Kolter, 2005; McCrate, Zhou, Reichhardt, \& Cegelski, 2013; Vlamakis, Chai, Beauregard, Losick, \& Kolter, 2013). Although the composition of these matrices are diverse between different organisms, they typically contain, among others, proteins, polysaccharides, and extracellular DNA (eDNA) (Claessen et al., 2014; Gebbink et al., 2005; White, Gibson, Collinson, Banser, \& Kay, 2003; Zogaj, Bokranz, Nimtz, \& Römling, 2003). The matrix contributes to structural integrity of the multicellular community, while simultaneously providing protection against various stresses (DePas et al., 2013; Romero, Aguilar, Losick, \& Kolter, 2010; Scher, Römling, \& Yaron, 2005). While matrices are usually mentioned in the context of biofilms, streptomycetes also make extracellular substances that contribute to morphology. Kim and Kim (2004) already demonstrated that pellets of $S$. coelicolor were susceptible to DNAse treatment. In addition to eDNA, a role for hyaluronic acid in pellet integrity was proposed. Interfering with these matrix components made pellets fragile, leading to their (partial) disintegration (Kim \& Kim, 2004). These data lead to a model in which an extracellular matrix, consisting of at least eDNA and hyaluronic acid, contributes to morphology of Streptomyces pellets by acting as an adhesive. The eDNA component of this matrix is probably released in the environment during PCD occurring in the central part of the pellet, and trapped within the pellet core.

Another component of such an extracellular matrix is the polymer produced by the cellulose synthase-like protein CslA (de Jong, Wösten, Dijkhuizen, \& Claessen, 2009; Xu et al., 2008). CslA was discovered as an interaction partner of DivIVA (Xu et al., 2008). CslA is conserved in streptomycetes and synthesizes a polymer consisting of $\beta$-(1-4) glycosidic bonds, consistent with a cellulose-like polymer, at hyphal tips and branch sites. The exact nature of the polysaccharide is still unclear. Deletion of the $c s l A$ gene has a pronounced effect on the morphology of liquid-grown mycelia, with a much more dispersed growth than wild-type cells (Fig. 1.1; $\mathrm{Xu}$ et al., 2008). This suggests that the polymer produced by CslA contributes to pellet architecture, perhaps by acting as an adhesive. Interestingly, deletion of the downstream-located gene $g l x A$, which encodes a putative galactose-like oxidase, also results in an open mycelial morphology (our unpublished data), and GlxA may modify the CslA-synthesized polysaccharide. Indeed, both genes are transcriptionally coupled under most growth 
conditions (Liman, Facey, van Keulen, Dyson, \& Del Sol, 2013; Xu et al., 2008).

CslA is required for the hyphal attachment to surfaces (de Jong, Wösten, et al., 2009). This attachment coincides with the formation of an extracellular matrix, which is characterized by fimbrial structures that protrude from the cell surface of the adhering hyphae. Notably, while the absence of CslA had no visible effect on the number of fimbriae, their connection to the cell surface was considerably weakened. Further characterization of these fimbriae indicated that they were largely composed of bundled amyloid fibrils of so-called chaplin proteins (de Jong, Wösten, et al., 2009). Without chaplins, much thinner fibrils were observed that were susceptible to treatment with cellulase. This enzyme could also release wild-type fimbriae from the cell surface. This led to a model in which the CslA-produced polysaccharide provides a scaffold for fimbriae formation, while also contributing to their anchoring. It is tempting to speculate that the formation of pellets is also mediated via attachment and aggregation. Rather than connecting hyphae to surfaces, fimbriae would now mediate interactions between adjacent hypha, leading to a compact pellet structure. Consistent with this idea is the observation that the formation of pellets is not only disturbed without cslA but also in the absence of chaplins (M.L.C. Petrus \& DC, unpublished data).

\subsection{Proteins that control liquid-culture morphogenesis}

Presently, there is relatively little known of the proteins that are specifically involved in the control of submerged sporulation. Indeed, scanning the literature shows that of close to 500 publications on the topic of sporulation of Streptomyces, fewer than 20 of those are primarily dedicated to the biology of submerged sporulation (PubMed search as of February 2014). The first studies into proteins that control submerged sporulation were done in the mid-90s of the previous century. Comparison of protein expression profiles between liquid-grown cultures prior to and at the onset of submerged sporulation identified a 52-kDa sporulation-specific protein, designated EshA (for extension of sporogenic hyphae), as a cyclic nucleotide-binding protein that is expressed during the first $12 \mathrm{~h}$ of submerged sporulation and that is required for growth of sporogenic hyphae at an early stage of morphogenesis of S. griseus (Kwak \& Kendrick, 1996). Interestingly, while esh $A$ null mutants were inhibited in the elongation of sporogenic hyphae from new branch points in submerged culture, spore 
chains were instead formed ectopically in vegetative hyphae, apparently by accelerating septation and spore maturation at the preexisting vegetative filaments (Kwak \& Kendrick, 1996). This suggests that EshA is required for growth of sporogenic hyphae but not for sporulation per se. Saito, Ochi, and colleagues demonstrated that EshA also plays a role in the control of antibiotic production, whereby deletion of esh $A$ inhibits production of actinorhodin but not of prodigionines in S. coelicolor (Kawamoto et al., 2001) and streptomycin production in S. griseus (Saito, Matsubara, Watanabe, Kato, \& Ochi, 2003). Furthermore, esh $A$ is conditionally required for sporulation on surface-grown cultures of $S$. griseus, but not for S. coelicolor (Saito, Matsubara, et al., 2003). Interestingly, EshA forms larger protein complexes, potentially forming icosahedron-like structures. While the protein and its orthologue MMPI of Mycobacterium leprae were reported to be membrane-associated (Kwak, McCue, Trczianka, \& Kendrick, 2001; Winter et al., 1995), consistent with the presence of putative transmembrane helices, at least the multimeric complexes were primarily identified in the cytoplasm of S. griseus (Saito, Matsubara, et al., 2003). While the exact role of EshA is still unclear, large amounts of dNTPs accumulate in esh $A$ null mutants, coinciding - and consistentwith strongly reduced rates of DNA synthesis, in particular at a time coinciding with the onset of development (Saito, Matsubara, et al., 2003). It therefore seems likely that EshA plays a role in the activation of DNA synthesis during the onset of sporulation-specific cell division. It should be noted that $e s h A$ lies immediately upstream of the genes for synthesis of the volatile organic compound (VOC) 2-methylisoborneol (Wang \& Cane, 2008), and analysis in String (www.string-embl.de) reveals strong phylogenetic linkage to the gene encoding the germacradienol/geosmin synthase GeoA, which synthesizes the VOC geosmin (Gust, Challis, Fowler, Kieser, \& Chater, 2003). It is yet unclear what the functional relevance is of this surprising linkage between EshA and VOC biosynthetic genes in streptomycetes.

Another protein with major impact on liquid-culture morphology is HyaS, which affects pellet morphology and integrity (Koebsch, Overbeck, Piepmeyer, Meschke, \& Schrempf, 2009). This protein is conserved in streptomycetes and produced in liquid-grown cultures. HyaS associates with substrate hyphae and induces tight fusion-like contacts between hyphae (Koebsch et al., 2009). Deletion of hyaS in S. lividans resulted in irregularly shaped pellets, which were less dense than those of the parental strain. Interestingly, the $\mathrm{C}$-terminal part of the HyaS protein possesses amine 
oxidase activity, which is required for normal pellet morphology. Koebsch and colleagues speculate that this enzyme activity might induce cross-linking with other hyphae-associated protein(s) or compounds, in a similar manner as the eukaryotic cell surface-located lysyl oxidases are involved in matrix remodeling (Lucero \& Kagan, 2006).

On searching for proteins that were able to suppress hypersporulation of a spontaneous $S$. griseus mutant at high copy number, Kawamoto and Ensign identified SsgA as an important submerged sporulation-related protein (Kawamoto \& Ensign, 1995). It was soon discovered that SsgA functions by stimulating fragmentation of hyphae by activating septum formation (Kawamoto, Watanabe, Hesketh, Ensign, \& Ochi, 1997), and SsgA is required for both solid- and liquid-culture sporulation of streptomycetes (Jiang \& Kendrick, 2000; van Wezel, van der Meulen, et al., 2000; Yamazaki, Ohnishi, \& Horinouchi, 2003). On solid media, ssgA null mutants display a conditional "white" (nonsporulating) phenotype, as they are able to produce spores on mannitol-containing medium, but not in the presence of glucose (Jiang \& Kendrick, 2000; van Wezel, van der Meulen, et al., 2000). Although many early developmental (bld) mutants are carbon source-dependent (Merrick, 1976; Pope, Green, \& Westpheling, 1996), such dependence is very rare among whi mutants and this may reflect the fact that SsgA also controls submerged sporulation by sporogenic vegetative hyphae. The function of SsgA is discussed in detail in the next chapter.

It is likely that more genes are involved in the control of morphogenesis. For example, nonpelleting mutants were obtained after selection for such a phenotype in continuous cultures (M. Roth, DvD, \& GPvW, unpublished data), and previous work identified several spontaneous mutants of $S$. griseus that were affected specifically in submerged sporulation (Kawamoto \& Ensign, 1995; Kwak \& Kendrick, 1996). Apparently, such mutants are readily obtained, and many have not yet been characterized, strongly suggesting that much is yet to be learned about proteins that control submerged morphogenesis.

\subsection{Surface modification of Streptomyces spores}

Streptomyces spores formed in submerged cultures are decorated by a pattern of pairwise aligned rods, called the rodlet layer (Claessen et al., 2004). This layer, which apparently forms the same mosaic as that found on aerial spores, renders the surface of spores hydrophobic. Assembly of the rodlet layer involves two classes of proteins, rodlins (Claessen et al., 2002) and chaplins 
(Claessen et al., 2003; Elliot et al., 2003). The chaplin proteins form the main building blocks of the rodlet layer, by assembling into thin fibrils that are aligned by the rodlin proteins into wild-type rodlets (Petrus \& Claessen, 2014). Indeed, without rodlins, the chaplin fibrils are randomly deposited on the spore surface. Recent evidence indicates that chaplins self-assemble into an asymmetric fibrillar membrane when confronted with a hydrophobichydrophilic interface (Bokhove et al., 2013; Ekkers, Claessen, Galli, \& Stamhuis, 2014). The hydrophilic side of this membrane is relatively smooth, while the hydrophobic side has a fibrillar appearance. While such an interface is present when hyphae grow out of the aqueous environment into the hydrophobic air, it is absent in sporogenic hyphae formed in liquid, such as those of S. griseus or S. venezuelae. This strongly implies that other factors contribute to the assembly process, at least in liquid environments. This is not uncommon for other fibril-forming proteins, including the fungal equivalents of the chaplins, called hydrophobins (Wösten, 2001). Here, the assembly of the SC3 hydrophobin from the filamentous fungus Schizophyllum commune is stimulated by schizophyllan, one of the glycans present in the cell wall (Scholtmeijer, de Vocht, Rink, Robillard, \& Wösten, 2009). Also, SC3 assembly could be induced when the concentration of the monomers was increased. In fact, this makes it tempting to speculate that the schizophyllan binds to hydrophobin monomers, which locally increases the concentration thereby initiating self-assembly. Notably, the polymer produced by CslA at the hyphal tip could have a similar role, which in particular in liquid environments could be critical (Chater et al., 2010; de Jong, Wösten, et al., 2009; Xu et al., 2008). However, this awaits further experimental evidence.

\section{THE SsgA-LIKE PROTEINS}

\subsection{SsgA-like proteins and morphotaxonomy of actinomycetes}

SsgA is a small $15-\mathrm{kDa}$ protein that has so far only been found in the streptomycetaceae Streptomyces and Kitasatospora. Homologues of SsgA-the SsgA-like proteins or SALPs - are found in all of what may be considered as morphologically complex actinomycetes, with a suggestive correlation between the number of SALPs and the number of spores produced per spore chain: species producing single spores (e.g., Micromonospora, Salinispora) typically have a single SALP, those producing short spore chains (e.g., Sacharopolyspora) typically have two SALPs, and those forming spore 
chains (Streptomyces) or sporangia (Frankia) have multiple SALPs (Girard et al., 2013; Traag \& van Wezel, 2008). Members of the SALP family of proteins are typically between 130 and 145 aa long, with 30-50\% aa identity between the different family members. S. coelicolor contains seven SALPs (SsgA-G; Noens et al., 2005), of which SsgA, SsgB, and SsgG play a role in septum-site localization. SsgB is the archetypal SALP and functions by recruiting FtsZ to septum sites during the onset of sporulation-specific cell division (see below). The crystal structure of $\mathrm{SsgB}$ from Thermobifida fusca (Xu et al., 2009) revealed a bell-shaped trimer with-surprisingly—strong similarity to the structure of mitochondrial RNA-binding proteins MRP1 and MRP2 (Schumacher, Karamooz, Zikova, Trantirek, \& Lukes, 2006) and ssDNA-binding protein PBF-2 (Desveaux, Allard, Brisson, \& Sygusch, 2002). Recently, a novel structural homologue of SsgB was identified in the spirochete Borrelia burgdorferi, a pathogen that causes lyme borreliosis (Bhattacharjee et al., 2013). The B. burgdorferi OspE protein recruits the complement regulator $\mathrm{FH}$ to the bacterial cell wall, which then results in immune evasion (Bhattacharjee et al., 2013). Suggestively, as discussed below $\mathrm{SsgB}$ also functions by recruiting a protein, in this case FtsZ to the site of cell division (Willemse, Borst, de Waal, Bisseling, \& van Wezel, 2011).

$\mathrm{SsgB}$ is extremely well conserved in streptomycetes, with typically a maximum of one amino acid change between the orthologues, while at the same time the homology between orthologues in different genera is low (around $40 \%$ aa identity). This unique feature was used as a novel taxonomic analysis of actinomycetes to complement $16 \mathrm{~S}$ rRNA-based taxonomy (Girard et al., 2013). Phylogenetic analysis of the SsgA and SsgB proteins in streptomycetes showed that on the basis of the conservation of these proteins, streptomycetes fall apart into two subclasses, which are also distinct in terms of liquid-culture morphogenesis. The first class consists of species that produce mycelial clumps but fail to produce submerged spores, which cluster in the NLSp (no liquid-culture sporulation) branch, and the second form the LSp (liquid-culture sporulation) branch of the streptomycetes. Strikingly, Streptomyces species of the LSp type have an SsgB orthologue with a Thr128, while those of the NLSp type have an $\mathrm{SsgB}$ with Gln128. The exception to the rule is Streptomyces avermitilis, which (as far as we know) does not sporulate in submerged cultures, but contains SsgB variant T128. This apparently correlates with the absence in $S$. avermitilis of $\mathrm{SsgG}$, which is functionally related to $\mathrm{SsgB}(\mathrm{GPvW}$, unpublished data). 


\subsection{How does SsgA control hyphal morphogenesis?}

SsgA localizes to sites where cell wall remodeling is required and in both vegetative and aerial hyphae, namely at sites for germination, branching, and septum formation (Noens et al., 2007). SsgA activates all of these processes, although the precise mechanism is not clear. In terms of germination, SsgA-overexpressing strains have been shown to form on average around 2.5 germ tubes per spore (against 2.0 germ tubes per spores for the wild-type strain and 1.7 for $\operatorname{ssg} A$ null mutants), whereby sometimes even five or more germ tubes emerge from a single spore (Noens et al., 2007). Second, enhanced expression of the protein stimulates branching, whereby many short branches are formed that fail to grow out to normal length (van Wezel, van der Meulen, et al., 2000). The best-studied activity of SsgA relates to its ability to activate cell division, and overexpression of SsgA results in a large number of very thick septa produced in vegetative hyphae (van Wezel, van der Meulen, et al., 2000). Thus, SsgA activates cell wall remodeling processes, perhaps via physical modification of the peptidoglycan. The latter is among others suggested by the strongly increased sensitivity of SsgA-overexpressing cells to lysis ( $\mathrm{GPvW}$, unpublished data).

The effect of SsgA on hyphal morphology is highly pleiotropic, as underlined by two further observations. First, enhanced expression of SsgA does not only stimulate cell division, but enforces pleiotropic changes of the morphology of the hyphae. Hyphae become twice as wide as normal vegetative hyphae (around $1 \mu \mathrm{m}$ instead of $0.5 \mu \mathrm{m}$ ), giving the appearance of aerial hyphae, and submerged sporulation is observed in S. coelicolor, which normally only sporulates in surface-grown cultures (van Wezel, van der Meulen, et al., 2000). Second, microarray studies revealed that some 1000 genes were more than twofold deregulated in an $s s g A$ null mutant of $S$. coelicolor, and most notably almost all developmental genes (bld, whi), as well as $\operatorname{divIVA}$ (tip growth), ftsI (cell division), chp and $r d l$ for the chaplin and rodlin spore coat proteins, genes for the components of the Sec and Tat secretion systems, and many genes involved in DNA segregation and topology (Noens et al., 2007). The remarkable upregulation of these genes indicates a major upset in the control of development and secretion.

Finally, SsgA also has a major impact on antibiotic production, although it is likely that this is due to its influence on morphology. Colonies that overexpress the SsgA protein fail to produce actinorhodin, while production of prodigionines (Red) is strongly enhanced (van Wezel, White, Hoogvliet, \& Bibb, 2000). In fact, in batch fermentations, Red production is some $20-50$ 
times enhanced as compared to the wild-type strain (van Wezel et al., 2009). The most logical explanation is that SsgA induces fragmentation and fast growth, which is detrimental for the production of antibiotics that are produced later during growth, such as Act (Gramajo, Takano, \& Bibb, 1993). Red production occurs during vegetative growth (Takano et al., 1992) and (perhaps as a consequence) benefits from fast and fragmented growth (van Wezel et al., 2009).

\subsection{SsgA and SsgB control the localization of FtsZ}

Like SsgA, SsgB is also required for sporulation (Keijser et al., 2003), and it is part of the cell division complex (divisome) during sporulation-specific cell division. These studies were done in surface-grown cultures, but most likely translate to submerged sporulation. However, this needs to be experimentally validated. During sporulation, $\mathrm{SsgB}$ functions by actively recruiting FtsZ, which forms the contractile cell division ring (Bi \& Lutkenhaus, 1991), to division sites. SsgB localizes to future division sites prior to FtsZ, and live imaging showed that soon after the appearance of $\mathrm{SsgB}$ foci, also Fts $Z$ arrives at these sites, after which they fully colocalize during the entire division process (Willemse et al., 2011). SsgB interacts with FtsZ and activates polymerization of FtsZ protofilaments in vitro, resulting in 450-nm-long FtsZ filaments (Willemse et al., 2011). Different modes of action have been described for proteins involved in FtsZ filament formation, such as ZipA, which stimulates the formation of filament networks (RayChaudhuri, 1999), or ZapA, which promotes bundling of the filaments (Gueiros-Filho \& Losick, 2002; Low, Moncrieffe, \& Löwe, 2004). The activity of SsgB is mechanistically most similar to that of ZipA.

The next step in understanding the role of the SALPs in the control of cell division in Streptomyces is to find out how SsgB itself is localized. SsgA plays a role in this process during sporulation in solid-grown cultures, and the two proteins transiently interact prior to the start of division. Little is known of how cell division is controlled during vegetative growth. Overexpression of SsgA in fact \triggers an aerial-type cell division in vegetative hyphae, leading to cell fission (fragmentation, submerged sporulation); this likely requires an intact divisome, while vegetative cell division takes place in the absence of canonical cell division proteins like FtsI and FtsW (McCormick, 2009; Mistry, Del Sol, Wright, Findlay, \& Dyson, 2008). We anticipate that the (size of the) nucleoid may play an important role in spatially determining the sites for division, as control systems should be 
in place that prevent septum formation over nonsegregated chromosomes, as is the case in all bacterial systems (Wu \& Errington, 2012). This idea waits further experimental testing.

\section{ENVIRONMENTAL AND REACTOR CONDITIONS}

So far, we have mainly focused on the genetic factors influencing morphology of streptomycetes in liquid-grown environments. However, mycelial morphology and development is also strongly influenced by environmental factors and by the reactor set-up (Fig. 1.3). Such factors include nutrients (Jonsbu, McIntyre, \& Nielsen, 2002; Naeimpoor \& Mavituna, 2000), pH (Glazebrook, Vining, \& White, 1992), viscosity (O'Cleirigh, Casey, Walsh, \& O’Shea, 2005), agitation (Ayazi Shamlou, Makagiansar, Ison, Lilly, \& Thomas, 1994; Belmar-Beiny \& Thomas, 1991; Cui, van der Lans, \& Luyben, 1997; Heydarian, Mirjalili, \& Ison, 1999), dissolved oxygen (DO) levels (Vecht-Lifshitz, Magdassi, \& Braun, 1990), and surface tension (Vecht-Lifshitz, Magdassi, \& Braun, 1989). Here, we will discuss the environmental factors that affect pellet morphology.

\subsection{Culture heterogeneity}

Heterogeneity is a common trait in microbial communities, which probably contributes to increased fitness (Smits, Kuipers, \& Veening, 2006).

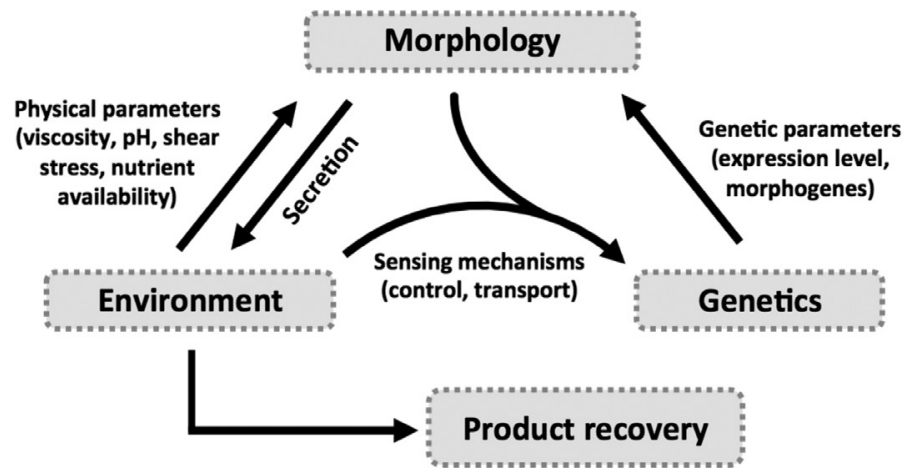

Figure 1.3 Streptomyces morphology is determined by environmental and genetic determinants. An important factor for the behavior and productivity of streptomycetes in bioreactors is morphology, which is influenced by physical and genetic parameters. In turn, morphology and growth affect the environmental conditions, such as rheology and nutrient composition, and reactor conditions and morphology affect the global gene expression profile. 
However, in industrial settings, heterogeneity is an unwanted feature, because it contributes to an unpredictable outcome of the fermentation process. Mycelia growing in flasks or bioreactors are highly heterogeneous in terms of morphology. One cause of heterogeneity is asynchronous initiation of germination and subsequent outgrowth of spores (Hardisson, Manzanal, Salas, \& Suárez, 1978). Analysis of Streptomyces antibioticus indicated that approximately $20 \%$ of the spores showed no visible signs of germination $5 \mathrm{~h}$ after inducing this process (Hardisson et al., 1978). The asynchrony might result from substances that are released during spore germination, which would inhibit germination of neighboring spores (Aoki, Matsumoto, Kawaide, \& Natsume, 2011; Grund \& Ensign, 1985).

Notably, heterogeneity also develops during growth. This heterogeneity is heritable and characterized by the presence of two populations of pellets that differ in size (Petrus, van Veluw, Wösten, \& Claessen, 2014; van Veluw et al., 2012). This heterogeneity was also observed when spore germination was synchronized, or when cultures were inoculated with precultured mycelia. Analysis of a range of different streptomycetes indicated similar behavior with two different populations, regardless of strain, culturing conditions, or culture age. Interestingly, the average pellet size of the population of small pellets was rather constant throughout growth, and similar between strains (van Veluw et al., 2012). In contrast, the average size of the larger pellets was variable. This indicates that environmental parameters known to influence morphology, such as flask geometry, stirring speed, and medium composition, in particular affect the population of large pellets (Celler, Picioreanu, van Loosdrecht, \& van Wezel, 2012; Tough \& Prosser, 1996).

\subsection{Nutrients and morphology}

The availability and diversity of nutrients strongly affects Streptomyces morphogenesis and antibiotic production (Bibb, 2005; Gubbens, Janus, Florea, Overkleeft, \& van Wezel, 2012; Sánchez et al., 2010; Ueda et al., 2000; van Wezel \& McDowall, 2011). The frequency of branching of the vegetative hyphae is strongly dependent on the growth conditions, whereby nutrientrich conditions favor branching, so as to allow acquisition of nutrients in the soil, while under nutrient-depleted conditions branching is reduced, and growth is dictated by tip extension, which favors the formation of so-called searching hyphae (Bushell, 1988). Both branching and cross-wall formation reduce hyphal strength (McCormick, Su, Driks, \& Losick, 1994; 
Wardell et al., 2002). As discussed above, overexpression of SsgA leads to strongly enhanced cell division in vegetative hyphae, coinciding with fragmentation, which is often seen occurring at the septa.

The critical role of sugar metabolism on morphogenesis is underlined by the fact that mutation of any of a range of different sugar transport systems results in vegetative arrest on surface-grown cultures: in essence, they are bld genes (Chater et al., 2010; Colson et al., 2008; Rigali et al., 2006; Seo, Ohnishi, Hirata, \& Horinouchi, 2002). In an attempt to create a more reproducible morphology, Streptomyces akiyoshiensis was grown on various carbon sources (Glazebrook et al., 1992). The largest pellets were obtained by growth on lactose (over $600 \mu \mathrm{m}$ ), while growth on glucose resulted in the smallest pellets (less than $200 \mu \mathrm{m}$ ). Growth on either of these carbon sources resulted in some fivefold lower biomass as compared to growth on starch, which highlights the complex link between growth and morphology. The optimal carbon source for production varies between species. Mannitol was the best carbon source for the geosmin production by Streptomyces halstedii (Schrader \& Blevins, 2001), a combination of fructose and mannose was best for rapamycin production by S. hygroscopicus (Kojima, Cheng, Mohan, \& Demain, 1995), and glycerol was needed for good production of clavulanic acid by S. clavuligerus (Romero, Liras, \& Martin, 1984). Media composition also had a major impact on the hyphal stability of S. clavuligerus, with cells cultured in media containing glutamate, glycerol, and ammonia being more shear-resistant as compared to cells grown in different media (Roubos, Krabben, Luiten, Verbruggen, \& Heijnen, 2001).

\subsection{Fragmentation}

The mechanical forces encountered in the submerged environment leads to fragmentation of the pellets, which occurs on a stochastic basis and counterbalances the size increase of a growing pellet (Fig. 1.4). The mechanical forces in a reactor originate from the combination of agitation, gas holdup, and the rheology of the culture fluid (Olmos et al., 2013; van't Riet \& Tramper, 1991). Especially the water swirls, or eddies, which arise under turbulent flow velocities, stretch hyphae in opposite direction with fragmentation as a logical result (Ayazi Shamlou et al., 1994; Heydarian, Ison, Lilly, \& Ayazi Shamlou, 2000). For filamentous microorganisms, the importance of understanding the relationship between the mechanical forces and growth is nontrivial because the mycelia themselves influence the rheology of the culture broth. Entanglement of the mycelia can 


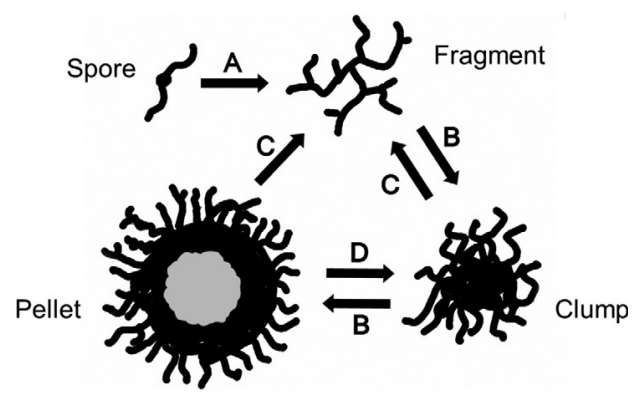

Figure 1.4 Proposed life cycle of a Streptomyces pellet. Germination (A) leads to the formation of a mycelial network that grows (B) into a clump. Continued growth leads to the formation of dense pellets. Clumps and pellets can also fragment (C) or disintegrate ( $D$; in particular for pellets) to give rise to new mycelia or clumps. The gray area represents the "dead" core of a large pellet.

dramatically increase the viscosity, which affects the shear stress and can reduce the transfer of heat and nutrients (Metz \& Kossen, 1977). This process occurs when the biomass grows as a mat, but it has also been observed when pellets are the predominant morphology (Mehmood, Olmos, Marchal, Goergen, \& Delaunay, 2010).

Fragmentation can occur as small hyphal fragments detach from the periphery of the pellet, or via disintegration of pellets into multiple parts (Cui et al., 1997; Kelly, Grimm, Jonas, Hempel, \& Krull, 2006). For an exposed hypha to break, the force applied must be greater than its tensile strength. Studies using a blender showed that the fungus Penicillium notatum is about four times more likely to break in the middle of a hypha than at the septum (Savage \& Brook, 1946). A correlation exists between the likelihood of hyphal breakage and the presence of vacuoles, which are hypothesized to cause localized weak spots (Papagianni, Mattey, \& Kristiansen, 1999; Paul, Kent, \& Thomas, 1994). However, in Streptomyces vacuoles are rarely seen in vegetative mycelia (Wildermuth, 1970). Notably, stimulating septation via overproduction of SsgA increases fragmentation of streptomycetes, although these septa more resemble sporulation-type septa (see above). Conversely, less branching in Saccharopolyspora erythraea decreased fragmentation (Wardell et al., 2002). Because crosswalls are often found near branch points, these results suggest that they in fact represent local weak spots along the hyphae.

Disintegration of preexisting pellets is the second mechanism by which new pellets can be established. The combined strength of the forces that keep a pellet together is much larger than the tensile strength of individual 
hyphae. It seems therefore that this process can only occur when the interactions between hyphae are diminished. This can be caused by a changing environment, for example, a change in $\mathrm{pH}$ (Glazebrook et al., 1992), but also due to a lack of nutrients, oxygen, or the buildup of toxins that induce lysis in the center of a pellet (Hille, Neu, Hempel, \& Horn, 2005; Papagianni, 2004). Notably, the susceptibility to fragmentation changes over the course of growth. Generally, the pellet size seems to increase during exponential growth, but decreases when entering end-log or stationary phase (Reichl, King, \& Gilles, 1992; van Veluw et al., 2012). Susceptibility of S. erythraea to fragmentation is almost twice as high in the stationary phase compared to exponential growing cells (Stocks \& Thomas, 2001). This probably relates to PCD in the center of a pellet (Manteca, Sanchez, Jung, Schwämmle, \& Jensen, 2010; Rioseras, López-García, Yagüe, Sánchez, \& Manteca, 2013), consistent with the observation that in filamentous fungi pellets become hollow in the center, severely reducing stability (el-Enshasy, Hellmuth, \& Rinas, 1999). This hollowing was observed in cross-sections of a pellet of Streptomyces tendae with a diameter of $120 \mu \mathrm{m}$ (Braun \& Vecht-Lifshitz, 1991), but it is unclear in how far this occurs in pellets of other streptomycetes.

\subsection{Relationship between agitation, oxygenation, morphology, and productivity}

As a rule of thumb, and expectedly, more vigorous stirring leads to smaller pellet size (Bellgardt, 1998; Ohta, Park, Yahiro, \& Okabe, 1995; Tough \& Prosser, 1996). However, the morphology of Streptomyces fradiae showed an inverse correlation, with low or medium shear stress favoring pelleted growth, while high shear stress caused mycelia of $S$. fradiae to fragment. Interestingly, the pellets grown under low shear stress continued to increase in size, while under medium shear a decrease in size was observed after the exponential growth phase (Heydarian et al., 1999; Tamura, Park, Toriyama, \& Okabe, 1997). Because faster mixing also increases mass transfer, it typically increases growth rate and biomass accumulation (Heydarian et al., 1999) and can therefore also have a major impact on the production of secondary metabolites (Cerri \& Badino, 2012; Heydarian et al., 1999; Rosa, Baptista Neto, Hokka, \& Badino, 2005). Most studies show an optimum stirring speed for production of the metabolite of interest, where initially the production increases with stirrer speed and then decreases again at very high speeds (Heydarian et al., 1999; Large, Ison, \& Williams, 1998; Mehmood et al., 2010; Roubos, Krabben, de Laat, Babuška, \& Heijnen, 
2002). This decrease in yield is most likely the result of cell damage caused by high shear conditions, as illustrated by the comparison of growth and lipase production of $S$. fradiae in an airlift with a stirred vessel. Leakage of lipase into culture fluid, indicative of cell damage, was exclusively observed in stirred vessels (Ohta et al., 1995).

Because oxygen transfer is closely linked with agitation, the effects of the one from the other need to be distinguished (Bartholomew, Karow, Sfat, \& Wilhelm, 1950a, 1950b; Mehmood et al., 2010; Rocha-Valadez, Albiter, Caro, Serrano-Carreón, \& Galindo, 2007; Shioya, Morikawa, Kajihara, \& Shimizu, 1999). Due to its low solubility and the high energetic cost of antibiotic production, DO levels are often rate-limiting and oxygendepleted in the center of a pellet (Hille et al., 2005; Olmos et al., 2013; Wucherpfennig et al., 2010). Fermentations in the presence of saturated DO levels increased the production of cephamycin by $S$. clavuligerus more than twofold (Yegneswaran, Gray, \& Thompson, 1991), increasing the DO levels using perfluorocarbon increased the production of actinorhodin by S. coelicolor about fivefold (Elibol \& Mavituna, 1999), and extra oxygen supplied by producing haemoglobin in S. erythraea increased the production of erythromycin (Brünker, Minas, Kallio, \& Bailey, 1998). These results clearly demonstrate the critical role that oxygen has on productivity.

DO levels also affect pellet morphology. Vecht-Lifshitz observed a proportional decrease of pellet size when DO levels were lower (Vecht-Lifshitz et al., 1990). From a biological perspective, regulation of the morphology by oxygen may be needed to balance the physical protection offered by the mycelium with the ability to produce secondary metabolites, which offer chemical protection. Biofilms of filamentous fungi are known to contain channels through which liquid and nutrients can flow toward the internal parts of these structures (Wimpenny, Manz, \& Szewzyk, 2000). They have recently also been identified in bacterial biofilms (Wilking et al., 2013). It will therefore be interesting to see if Streptomyces pellets also possess these "artery-like" structures.

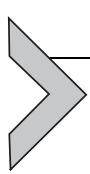

\section{MORPHOLOGY AND ANTIBIOTIC PRODUCTION}

\subsection{Impact of morphology on antibiotic production}

The formation of pellets is a major drawback for industrial applications, as pellets represent a slow-growing morphology (Liu, Yang, et al., 2013). Therefore, many efforts have focused on obtaining a more open or dispersed morphology. Addition of charged polymers like junlon or carbopol has been 
applied as a means to obtain a dispersed morphology (Harriott \& Bourret, 2003; Hobbs, Frazer, Gardner, Cullum, \& Oliver, 1989). These compounds probably interfere with the electrostatic properties of the cell wall, which prevents initial aggregation (Wargenau, Kampen, \& Kwade, 2013). Lowering the $\mathrm{pH}$ also influences the surface charge of the cell wall, thereby yielding a similar effect (Braun \& Vecht-Lifshitz, 1991; Wargenau et al., 2011). Increasing the viscosity of the broth also induces more fragmented growth because it increases shear stress, while reducing pellet-pellet collisions, which could also lead to their aggregation (O'Cleirigh et al., 2005). However, higher viscosity demands more energy input to obtain sufficient stirring, which increases production costs. For some products, mostly enzymes but also some antibiotics, dispersed growth can increase yields (van Wezel et al., 2006), while for the production of the majority of the antibiotics pelleted growth is preferred (Martin \& Bushell, 1996; Pickup \& Bushell, 1995). The latter often leads to a situation whereby morphology is suboptimal as a compromise to maintain relatively high antibiotic yields (Braun \& VechtLifshitz, 1991; Martin \& Bushell, 1996).

In surface-grown cultures of Streptomyces, there is a clear link between the production of antibiotics and the developmental cycle (Bibb, 2005; van Wezel \& McDowall, 2011). Well-established is the growth phase dependence of production, where the onset of synthesis usually occurs when growth stalls (Bibb, 2005; van Wezel \& McDowall, 2011). However, once activated, there apparently is no additional control; placing redD, the pathway-specific activator gene for production of prodigionines in $S$. coelicolor, under the control of the promoter of the gene for the global nitrogen regulator $(g \ln R)$ or a sporulation-specific sigma factor $(s i g F)$, ensures that production of the antibiotic is controlled by nitrogen or produced in aerial hyphae, respectively (van Wezel, White, et al., 2000). This implies that at least for some antibiotics, there are no metabolic limitations as to when or where they are produced, and therefore that restrictions on production imposed by growth and morphology-related control mechanisms can be overcome.

In submerged cultures, the linkage between mycelial morphology and production is exemplified by avermectin production by $S$. avermitilis, which is highest when small dense pellets were formed (Yin et al., 2008), and by the fact that a high-producing variant of Streptomyces noursei formed dense pellets, while the wild-type strain formed loose clumps (Jonsbu et al., 2002). Pellets were a prerequisite for the production of a hybrid antibiotic by S. lividans (Sarrà, Casas, Poch, \& Gòdia, 1999), and filtering of a culture 
of $S$. erythraea revealed that small pellets with a diameter below $88 \mu \mathrm{m}$ were unable to produce erythromycin (Martin \& Bushell, 1996). As discussed in Chapter 4, fragmentation of mycelia by enhanced expression of SsgA has a major effect on antibiotic production by $S$. coelicolor, with a block of Act production, while Red is massively upregulated, again underlining the major influence of morphology on production.

\subsection{PCD and antibiotic production}

Mycelial development in liquid-grown cultures may be more similar to that in surface-grown cultures than initially thought. Life/dead staining showed that the early mycelium is compartmentalized in $S$. coelicolor, similar to the initial mycelium in surface-grown cultures. A fraction of this early mycelium undergoes a process that strongly resembles PCD, with two rounds of PCD occurring during the Streptomyces life cycle (Manteca et al., 2011). After spore germination, a compartmentalized mycelium grows and then undergoes a first round of PCD (Manteca et al., 2011). The second round of PCD starts during the onset of development, which corresponds to the transition phase between exponential growth and stationary phase in liquid-grown cultures (Granozzi, Billetta, Passantino, Sollazzo, \& Puglia, 1990; Manteca, Fernandez, \& Sanchez, 2005). During PCD, specific nucleases are activated that are involved in degradation of chromosomal DNA (Fernandez \& Sanchez, 2002; Granozzi et al., 1990; Manteca, Fernandez, \& Sanchez, 2006; Rioseras et al., 2013). Following this PCD event, secondary mycelium emerges from the center of a pellet (Manteca, Alvarez, Salazar, Yagüe, \& Sanchez, 2008; Park, Tamura, Koike, Toriyama, \& Okabe, 1997). The secondary mycelium was found to be distinct from the initial mycelia by being multinucleated, which is again similar to solid cultures (Yagüe et al., 2014).

The idea that Streptomyces mycelia also undergo a developmental cycle in submerged cultures was suggested by the first microarray experiments done on S. coelicolor, which showed that the transcription of many developmental genes is switched on during the transition phase, which is the phase when growth slows down (Huang, Lih, Pan, \& Cohen, 2001). More recently, this was also shown by proteomic comparison of young and older mycelia, with early mycelium enriched in primary metabolic enzymes while proteins involved in secondary metabolism and those associated with development and sporulation were enriched in the multinucleated secondary mycelium (Manteca et al., 2010; Yagüe et al., 2014). Interestingly, many 
developmental genes are actively transcribed in the secondary mycelium, including several bld genes (i.e., bldB, bldC, bldM, bld $N$ ), but also those involved in formation of the rodlet layer $(\operatorname{ch} p C, \operatorname{ch} p D, \operatorname{ch} p E$, and $\operatorname{ch} p H$; Claessen et al., 2004; Manteca, Claessen, Lopez-Iglesias, \& Sanchez, 2007). The antibiotics undecylprodigiosin and actinorhodin were exclusively produced by the secondary mycelium in both solid- and liquid-grown cultures (Manteca et al., 2008). Various sporulation-specific genes are upregulated in older cultures (Huang et al., 2001; Yagüe et al., 2014). These data strongly suggest that liquid-grown mycelia als undergo differentiation. In fact, a small fraction of the mycelium appeared to be initiating a sporulation-like process, which is rarely seen for $S$. coelicolor (Rioseras et al., 2013). Indeed, overexpression of $w h i G$ or $s s g A$ induced a certain degree of submerged sporulation in submerged cultures of $S$. coelicolor (Chater et al., 1989; van Wezel, van der Meulen, et al., 2000).

A direct link between PCD and antibiotic production was revealed when it was established that cell wall-derived $\mathrm{N}$-acetylglucosamine (GlcNAc) acts as an important signaling molecule for the onset of development and antibiotic production in Streptomyces (Rigali et al., 2006, 2008). In the competitive soil habitat, postponing sporulation is important if sufficient nutrients are available, while during starvation sporulation and ensuing dispersal are essential for survival. In nature, GlcNAc is obtained from hydrolysis of the abundant natural polymer chitin by the chitinolytic system. For bacteria, GlcNAc is a favorable $\mathrm{C}$ - and $\mathrm{N}$-source, and a major constituent of cell wall peptidoglycan. Some 13 chitinases and chitosanases have been identified in S. coelicolor (Colson et al., 2007; Delic, Robbins, \& Westpheling, 1992; Saito, Fujii, \& Miyashita, 2003), and GlcNAc and glutamate are preferred over glucose in fermentations of S. coelicolor (van Wezel et al., 2009).

Under poor nutritional conditions such as on minimal media, supplementing GlcNAc accelerates both the onset of development and antibiotic production, suggesting that under these conditions GlcNAc signals nutrient stress, resulting in accelerated development. Conversely, in rich media, higher concentrations of GlcNAc block development and antibiotic production, thus resembling conditions that promote vegetative growth (Rigali et al., 2008). These growth conditions may thus resemble conditions of feast or famine in the natural environment, whereby GlcNAc would be derived from chitin in nutrient-rich soil (feast), or from the Streptomyces cell wall during PCD (famine), respectively. The secret appears to lie in the nature of the sugar transporters. Monomeric GlcNAc enters the cell via the NagE2 permease (Nothaft et al., 2010), which is part of the 
PEP-dependent phosphotransferase system (Postma, Lengeler, \& Jacobson, 1993; Titgemeyer et al., 1995), while chitobiose (dimeric GlcNAc), which is the subunit of chitin, enters via the ABC transporters Das ABC or NgcEFG (Colson et al., 2008; Nothaft et al., 2003; Saito et al., 2007; Schlösser, Jantos, Hackmann, \& Schrempf, 1999). Subsequently, internalized GlcNAc is converted by the enzymes $\mathrm{NagA}$ and $\mathrm{NagB}$ to glucosamine-6-phosphate (GlcN-6-P; Swiatek, Tenconi, Rigali, \& van Wezel, 2012), a central metabolite that can then enter glycolysis (as fructose-6P) or the pathway toward peptidoglycan synthesis.

GlcNAc-derived GlcN-6-P acts as an allosteric effector of the GntRfamily regulator DasR (Rigali et al., 2006), a highly global regulator that controls the GlcNAc regulon (Nazari et al., 2013; Rigali et al., 2006; Swiatek et al., 2012), but also the production of antibiotics (Rigali et al., 2008) and siderophores (Craig et al., 2012). GlcNAc-dependent nutritional signaling is most likely mediated through changes in the intracellular level of GlcN-6-P, which binds as a ligand to the GntR-family regulator DasR, leading to derepression of DasR-mediated control of antibiotic production (Rigali et al., 2008). Recent work showed that addition of phosphorylated sugars to growth media under phosphate limitation delays the occurrence of the second round of PCD and results in vegetative arrest, also preventing antibiotic production (Tenconi, Jourdan, Motte, Virolle, \& Rigali, 2012).

The pleiotropic DasR control network is well conserved in actinomycetes and can be manipulated to activate antibiotic production. Addition of GlcNAc to cultures of streptomycetes grown on nutrient-depleted media accelerates development and enhanced antibiotic production by many streptomycetes (Rigali et al., 2008). This concept can be applied to activate cryptic antibiotic gene clusters, which are not or poorly expressed under normal growth conditions (Baltz, 2008). Indeed, GlcNAc induces expression of the cpk gene cluster for the cryptic polyketide Cpk (Gottelt, Kol, Gomez-Escribano, Bibb, \& Takano, 2010; Rigali et al., 2008). Thus, understanding of the correlation between morphogenesis and antibiotic production may be employed for drug discovery approaches.

\section{OUTLOOK: THE CORRELATION BETWEEN MORPHOLOGY AND PRODUCTION}

As the producers of a wide range of medically important natural products, streptomycetes are very important microorganisms for the 
pharmaceutical industry (Baltz, 2008; Hopwood, 2007; Olano et al., 2009). Moreover, the streptomycetes also produce a plethora of extracellular enzymes that allow them to degrade almost any naturally occurring polymer, such as cellulose, mannan, chitin, xylan, starch, glycan, and agar (Anné et al., 2014; Vrancken \& Anné, 2009). However, as discussed in this review, streptomycetes grow as complex mycelia, which form a major bottleneck for industrial fermentations, as mycelial growth is associated with slow growth, culture heterogeneity, and high viscosity of the fermentation broth. These factors typically have an adverse effect on the yield. Heterologous expression in a host with better growth properties, such as Bacillus or yeast, is not an option for natural products with their very complex biosynthetic machinery and dependence on metabolic pathways, and also many actinomycetederived enzymes require actinomycete-specific machinery for proper folding, modification, and/or secretion and can therefore not be produced in a bioactive form in other hosts.

In terms of process engineering, the focus typically lies on changes in reactor or media conditions by, for instance, changing stirring speed, $\mathrm{pH}$, or nutrients, which have a pronounced effect on mycelial morphology. The advantage of this approach is that production yields for a particular compound can be improved fairly quickly. The disadvantage of this approach, however, is that results are difficult to translate to other streptomycetes, which often respond differently to changed conditions. These different responses might relate to, for instance, changes in cell wall composition, thereby influencing processes such as fragmentation and aggregation. In this respect, better understanding of the genetic factors involved in mycelial growth and architecture is a prerequisite to find general leads to improve streptomycetes in industry. However, while detailed insights into the molecular determinants of mycelial growth are critical for Streptomyces strain improvement, it is good to realize that the eventual productivity is determined by many different process technological and genetic parameters, whereby the effect of those parameters on productivity also largely depends on the product to be produced.

To predict the effect of culturing conditions as well as genetic factors on morphology, many different in silico models have been designed in the past (Liu, Xing, \& Han, 2005; Meyerhoff, Tiller, \& Bellgardt, 1995; Nielsen \& Villadsen, 1992; Tough \& Prosser, 1996; Yang, King, Reichl, \& Gilles, 1992). The older models largely focused on the influence of environmental factors on morphology, while genetics-based modeling had not been attempted (Kossen, 2000). Two new models of Streptomyces growth have 
been developed recently, which should lead to new impetus for modeling of Streptomyces growth and production (Celler et al., 2012; Nieminen, Webb, Smith, \& Hoskisson, 2013). Taking advantage of the incredible increase in computing power since the design of previous models, a three-dimensional in silico model was developed that allows visualization of growth of mycelial pellets with distinct morphologies (Celler et al., 2012). As parameters, this model includes among others oxygen diffusion, hyphal growth, branching, fragmentation, cross-wall formation, as well as a novel collision detection algorithm. The model was designed with industrial application in mind, allowing the user to change both physical and genetic parameters and see what the predicted effect is on pellet growth and yield. However, for such an approach to function as say an in silico test system for the fermentation industry, better insight into the genetic parameters that control morphogenesis is required, as well as an iterative process of modeling and experimentation.

In recent years, progress has been made in our understanding of the factors that govern mycelial growth, such as DivIVA, Scy, and CslA that coordinate tip growth, and the SsgA-like proteins that control hyphal morphology and cell division (Fig. 1.5). Better understanding of the genetic parameters that control growth should allow us to better control the

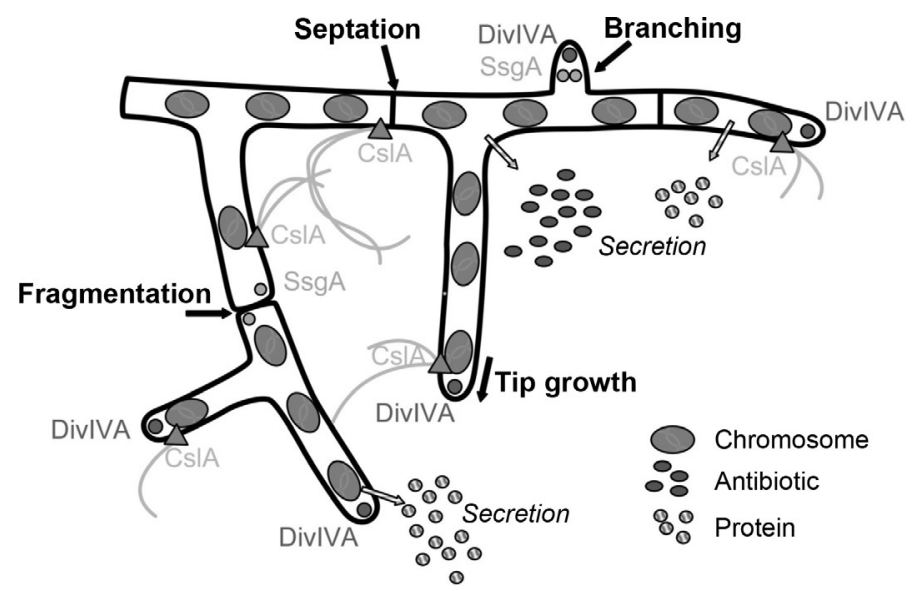

Figure 1.5 Control of growth of Streptomyces hyphae during fermentation. Branching frequency, tip growth rate, and fragmentation and aggregation are determined by the activity of morphoproteins and by growth conditions ( $\mathrm{pH}$, feedstock, stress). Morphology has a major impact on production and secretion. Some enzymes are secreted near the tips of the hyphae, as was shown recently for Tat substrates (Willemse et al., 2012), but it is unclear if this is also true for Sec substrates. Where antibiotics and other natural products are secreted is unknown. The drawn secretion sites are hypothetical. 
morphology of the mycelia in the fermentation broth. For example, fragmented growth of streptomycetes can be achieved by overexpression of SsgA, a property that is applied successfully in the industrial domain (van Wezel et al., 2006). For rational design of streptomycetes as production hosts, we will also need to understand how morphology affects yield. Live imaging showed that the Tat secretion system localizes highly dynamically and directly behind the tip complex (Celler, van Wezel, \& Willemse, 2013; Willemse et al., 2012), which suggested that fragmented growth and therefore increased number of apical sites, should favor secretion of Tat-dependent proteins. Indeed, secretion of the Tat substrate tyrosinase is strongly enhanced in fragmenting strains of $S$. coelicolor and S. lividans (van Wezel et al., 2006). The majority of the genetic studies have focused on the micromorphology, while little is known of how these proteins eventually influence macromorphology, such as the formation of clumps or pellets. Conversely, industrial strain engineering has led to mutant strains with often very good reactor properties, but with the many mutations that have occurred during the strain improvement programs, it is hard to identify the changes that may be exploited for rational strain engineering. One important approach that has become feasible in this era of genomics and next-generation sequencing is comparing the genome sequences and the global expression profiles of several generations of one production strain. This should allow identification of genes that may form novel targets for morphological engineering. Analysis of the mutations will provide valuable biological information that might be widely applicable to actinomycete production strains. In this way, the historically used black-box approach can be replaced by rational design of future production strains.

\section{ACKNOWLEDGMENTS}

We are grateful to Maureen Bibb, Mark Buttner, Martin Roth, and Erik Vijgenboom for discussions. The work is supported by VIDI and VICI grants from the Netherlands Technology Foundation STW to D.C. and G. P. v. W., respectively.

\section{REFERENCES}

Amijee, F., Allans, E. J., Waterhouse, R. N., Glover, L. A., \& Paton, A. M. (1992). Nonpathogenic association of L-form bacteria (Pseudomonas syringae pv. phaseolicola) with bean plants (Phaseolus vulgaris L.) and its potential for biocontrol of halo blight disease. Biocontrol Science and Technology, 2, 203-214.

Anné, J., Vrancken, K., Van Mellaert, L., Van Impe, J., \& Bernaerts, K. (2014 Aug). Protein secretion biotechnology in Gram-positive bacteria with special emphasis on Streptomyces lividans. Biochimica et Biophysica Acta, 1843(8), 1750-1761. http://dx.doi.org/10.1016/j. bbamcr.2013.12.023. Epub 2014 Jan 9. 
Aoki, Y., Matsumoto, D., Kawaide, H., \& Natsume, M. (2011). Physiological role of germicidins in spore germination and hyphal elongation in Streptomyces coelicolor A3(2). The Journal of Antibiotics, 64, 607-611.

Ayazi Shamlou, P., Makagiansar, H. Y., Ison, A. P., Lilly, M. D., \& Thomas, C. R. (1994). Turbulent breakage of filamentous microorganisms in submerged culture in mechanically stirred bioreactors. Chemical Engineering Science, 49, 2621-2631.

Bagchi, S., Tomenius, H., Belova, L. M., \& Ausmees, N. (2008). Intermediate filament-like proteins in bacteria and a cytoskeletal function in Streptomyces. Molecular Microbiology, 70, $1037-1050$.

Baltz, R. H. (2007). Antimicrobials from actinomycetes: Back to the future. Microbe, 2, 125-131.

Baltz, R. H. (2008). Renaissance in antibacterial discovery from actinomycetes. Current Opinion in Pharmacology, 8, 557-563.

Bartholomew, W. H., Karow, E. O., Sfat, M. R., \& Wilhelm, R. H. (1950a). Oxygen transfer and agitation in submerged fermentations. Effect of air flow and agitation rates upon fermentation of Penicillium chrysogenum and Streptomyces griseus. Industrial $\mathcal{E}$ Engineering Chemistry, 42, 1810-1815.

Bartholomew, W. H., Karow, E. O., Sfat, M. R., \& Wilhelm, R. H. (1950b). Oxygen transfer and agitation in submerged fermentations. Mass transfer of oxygen in submerged fermentation of Streptomyces griseus. Industrial \& Engineering Chemistry, 42, 1801-1809.

Bellgardt, K. H. (1998). Process models for production of $\beta$-lactam antibiotics. Advances in Biochemical Engineering/Biotechnology, 60, 153-194.

Belmar-Beiny, M. T., \& Thomas, C. R. (1991). Morphology and clavulanic acid production of Streptomyces clavuligerus: Effect of stirrer speed in batch fermentations. Biotechnology and Bioengineering, 37, 456-462.

Bewick, M. W., Williams, S. T., \& Veltkamp, C. (1976). Growth and ultrastructure of Streptomyces venezuelae during chloramphenicol production. Microbios, 16, 191-199.

Bhattacharjee, A., Oeemig, J. S., Kolodziejczyk, R., Meri, T., Kajander, T., Lehtinen, M. J., et al. (2013). Structural basis for complement evasion by Lyme disease pathogen Borrelia burgdorferi. The Journal of Biological Chemistry, 288, 18685-18695.

Bhosale, S. H., Rao, M. B., \& Deshpande, V. V. (1996). Molecular and industrial aspects of glucose isomerase. Microbiological Reviews, 60, 280-300.

Bi, E. F., \& Lutkenhaus, J. (1991). FtsZ ring structure associated with division in Escherichia coli. Nature, 354, 161-164.

Bibb, M. J. (2005). Regulation of secondary metabolism in streptomycetes. Current Opinion in Microbiology, 8, 208-215.

Bibb, M. J., Domonkos, A., Chandra, G., \& Buttner, M. J. (2012). Expression of the chaplin and rodlin hydrophobic sheath proteins in Streptomyces venezuelae is controlled by $\sigma(\mathrm{BldN})$ and a cognate anti-sigma factor, RsbN. Molecular Microbiology, 84, 1033-1049.

Bibb, M. J., Ward, J. M., \& Hopwood, D. A. (1978). Transformation of plasmid DNA into Streptomyces at high frequency. Nature, 274, 398-400.

Biró, S., Békési, I., Vitális, S., \& Szabó, G. (1980). A substance effecting differentiation in Streptomyces griseus. Purification and properties. European Journal of Biochemistry, 103, 359-363.

Bokhove, M., Claessen, D., de Jong, W., Dijkhuizen, L., Boekema, E. J., \& Oostergetel, G. T. (2013). Chaplins of Streptomyces coelicolor self-assemble into two distinct functional amyloids. Journal of Structural Biology, 184, 301-309.

Branda, S. S., Vik, S., Friedman, L., \& Kolter, R. (2005). Biofilms: The matrix revisited. Trends in Microbiology, 13, 20-26.

Braun, S., \& Vecht-Lifshitz, S. E. (1991). Mycelial morphology and metabolite production. Trends in Biotechnology, 9, 63-68. 
Brünker, P., Minas, W., Kallio, P. T., \& Bailey, J. E. (1998). Genetic engineering of an industrial strain of Saccharopolyspora erythraea for stable expression of the Vitreoscilla haemoglobin gene (vhb). Microbiology, 144, 2441-2448.

Bush, M. J., Bibb, M. J., Chandra, G., Findlay, K. C., \& Buttner, M. J. (2013). Genes required for aerial growth, cell division, and chromosome segregation are targets of WhiA before sporulation in Streptomyces venezuelae. mBio, 4, e00684-e00713.

Bushell, M. E. (1988). Growth, product formation and fermentation technology. In M. Goodfellow (Ed.), Actinomycetes in biotechnology (pp. 185-217). London: Academic Press.

Celler, K., Koning, R. I., Koster, A. J., \& van Wezel, G. P. (2013). Multidimensional view of the bacterial cytoskeleton. Journal of Bacteriology, 195, 1627-1636.

Celler, K., Picioreanu, C., van Loosdrecht, M. C., \& van Wezel, G. P. (2012). Structured morphological modeling as a framework for rational strain design of Streptomyces species. Antonie van Leeuwenhoek, 102, 409-423.

Celler, K., van Wezel, G. P., \& Willemse, J. (2013). Single particle tracking of dynamically localizing TatA complexes in Streptomyces coelicolor. Biochemical and Biophysical Research Communications, 438, 38-42.

Cerri, M. O., \& Badino, A. C. (2012). Shear conditions in clavulanic acid production by Streptomyces clavuligerus in stirred tank and airlift bioreactors. Bioprocess and Biosystems Engineering, 35, 977-984.

Chater, K. F. (1972). A morphological and genetic mapping study of white colony mutants of Streptomyces coelicolor. Journal of General Microbiology, 72, 9-28.

Chater, K. F., Biro, S., Lee, K. J., Palmer, T., \& Schrempf, H. (2010). The complex extracellular biology of Streptomyces. FEMS Microbiology Reviews, 34, 171-198.

Chater, K. F., Bruton, C. J., Plaskitt, K. A., Buttner, M. J., Mendez, C., \& Helmann, J. D. (1989). The developmental fate of $S$. coelicolor hyphae depends upon a gene product homologous with the motility sigma factor of B. subtilis. Cell, 59, 133-143.

Chater, K. F., \& Losick, R. (1997). Mycelial life style of Streptomyces coelicolor A3(2) and its relatives. In J. A. Shapiro, \& M. Dworkin (Eds.), Bacteria as multicellular organisms (pp. 149-182). New York: Oxford University Press, Inc.

Claessen, D., de Jong, W., Dijkhuizen, L., \& Wösten, H. A. B. (2006). Regulation of Streptomyces development: Reach for the sky! Trends in Microbiology, 14, 313-319.

Claessen, D., Rink, R., de Jong, W., Siebring, J., de Vreugd, P., Boersma, F. G., et al. (2003). A novel class of secreted hydrophobic proteins is involved in aerial hyphae formation in Streptomyces coelicolor by forming amyloid-like fibrils. Genes \& Development, 17, 1714-1726.

Claessen, D., Rozen, D. E., Kuipers, O. P., Søgaard-Andersen, L., \& van Wezel, G. P. (2014). Bacterial solutions to multicellularity: A tale of biofilms, filaments and fruiting bodies. Nature Reviews Microbiology, 12, 115-124.

Claessen, D., Stokroos, I., Deelstra, H. J., Penninga, N. A., Bormann, C., Salas, J. A., et al. (2004). The formation of the rodlet layer of streptomycetes is the result of the interplay between rodlins and chaplins. Molecular Microbiology, 53, 433-443.

Claessen, D., Wösten, H. A. B., van Keulen, G., Faber, O. G., Alves, A. M., Meijer, W. G., et al. (2002). Two novel homologous proteins of Streptomyces coelicolor and Streptomyces lividans are involved in the formation of the rodlet layer and mediate attachment to a hydrophobic surface. Molecular Microbiology, 44, 1483-1492.

Colson, S., Stephan, J., Hertrich, T., Saito, A., van Wezel, G. P., Titgemeyer, F., et al. (2007). Conserved cis-acting elements upstream of genes composing the chitinolytic system of streptomycetes are DasR-responsive elements. Journal of Molecular Microbiology and Biotechnology, 12, 60-66.

Colson, S., van Wezel, G. P., Craig, M., Noens, E. E., Nothaft, H., Mommaas, A. M., et al. (2008). The chitobiose-binding protein, DasA, acts as a link between chitin utilization and morphogenesis in Streptomyces coelicolor. Microbiology, 154, 373-382. 
Craig, M., Lambert, S., Jourdan, S., Tenconi, E., Colson, S., Maciejewska, M., et al. (2012). Unsuspected control of siderophore production by N-acetylglucosamine in streptomycetes. Environmental Microbiology Reports, 4, 512-521.

Cui, Y. Q., van der Lans, R. G., \& Luyben, K. C. (1997). Effect of agitation intensities on fungal morphology of submerged fermentation. Biotechnology and Bioengineering, 55, $715-726$.

Dalton, K. A., Thibessard, A., Hunter, J. I., \& Kelemen, G. H. (2007). A novel compartment, the 'subapical stem' of the aerial hyphae, is the location of a sigN-dependent, developmentally distinct transcription in Streptomyces coelicolor. Molecular Microbiology, 64, 719-737.

Daniel, R. A., \& Errington, J. (2003). Control of cell morphogenesis in bacteria: Two distinct ways to make a rod-shaped cell. Cell, 113, 767-776.

Daza, A., Martín, J. F., Dominguez, A., \& Gil, J. A. (1989). Sporulation of several species of Streptomyces in submerged cultures after nutritional downshift. Journal of General Microbiology, 135, 2483-2491.

de Jong, W., Manteca, A., Sanchez, J., Bucca, G., Smith, C. P., Dijkhuizen, L., et al. (2009). NepA is a structural cell wall protein involved in maintenance of spore dormancy in Streptomyces coelicolor. Molecular Microbiology, 71, 1591-1603.

de Jong, W., Wösten, H. A. B., Dijkhuizen, L., \& Claessen, D. (2009). Attachment of Streptomyces coelicolor is mediated by amyloidal fimbriae that are anchored to the cell surface via cellulose. Molecular Microbiology, 73, 1128-1140.

Delic, I., Robbins, P., \& Westpheling, J. (1992). Direct repeat sequences are implicated in the regulation of two Streptomyces chitinase promoters that are subject to carbon catabolite control. Proceedings of the National Academy of Sciences of the United States of America, 89, 1885-1889.

Dell'Era, S., Buchrieser, C., Couve, E., Schnell, B., Briers, Y., Schuppler, M., et al. (2009). Listeria monocytogenes $\mathrm{L}-$ forms respond to cell wall deficiency by modifying gene expression and the mode of division. Molecular Microbiology, 73, 306-322.

DePas, W. H., Hufnagel, D. A., Lee, J. S., Blanco, L. P., Bernstein, H. C., Fisher, S. T., et al. (2013). Iron induces bimodal population development by Escherichia coli. Proceedings of the National Academy of Sciences of the United States of America, 110, 2629-2634.

Derouaux, A., Halici, S., Nothaft, H., Neutelings, T., Moutzourelis, G., Dusart, J., et al. (2004). Deletion of a cyclic AMP receptor protein homologue diminishes germination and affects morphological development of Streptomyces coelicolor. Journal of Bacteriology, 186, 1893-1897.

Desveaux, D., Allard, J., Brisson, N., \& Sygusch, J. (2002). A new family of plant transcription factors displays a novel ssDNA-binding surface. Nature Structural \& Molecular Biology, 9, 512-517.

Ditkowski, B., Holmes, N., Rydzak, J., Donczew, M., Bezulska, M., Ginda, K., et al. (2013). Dynamic interplay of ParA with the polarity protein, Scy, coordinates the growth with chromosome segregation in Streptomyces coelicolor. Open Biology, 3, 130006.

Edwards, D. H., \& Errington, J. (1997). The Bacillus subtilis DivIVA protein targets to the division septum and controls the site specificity of cell division. Molecular Microbiology, 24, 905-915.

Ekkers, D. M., Claessen, D., Galli, F., \& Stamhuis, E. J. (2014). Surface modification using interfacial assembly of the Streptomyces chaplin proteins. Applied Microbiology and Biotechnology, 98, 4491-4501.

el-Enshasy, H., Hellmuth, K., \& Rinas, U. (1999). Fungal morphology in submerged cultures and its relation to glucose oxidase excretion by recombinant Aspergillus niger. Applied Biochemistry and Biotechnology, 81, 1-11.

Elibol, M., \& Mavituna, F. (1999). A remedy to oxygen limitation problem in antibiotic production: Addition of perfluorocarbon. Biochemical Engineering Journal, 3, 1-7. 
Elliot, M. A., Karoonuthaisiri, N., Huang, J., Bibb, M. J., Cohen, S. N., Kao, C. M., et al. (2003). The chaplins: A family of hydrophobic cell-surface proteins involved in aerial mycelium formation in Streptomyces coelicolor. Genes \& Development, 17, 1727-1740.

Erikson, D. (1947). Differentiation of the vegetative and sporogenous phases of the actinomycetes: The lipid nature of the outer wall of the aerial mycelium. Journal of General Microbiology, 1, 39-44.

Errington, J. (2013). L-form bacteria, cell walls and the origins of life. Open Biology, 3, 120143 .

Fernandez, M., \& Sanchez, J. (2002). Nuclease activities and cell death processes associated with the development of surface cultures of Streptomyces antibioticus ETH 7451. Microbiology, 148, 405-412.

Flärdh, K., \& Buttner, M. J. (2009). Streptomyces morphogenetics: Dissecting differentiation in a filamentous bacterium. Nature Reviews Microbiology, 7, 36-49.

Flärdh, K., Richards, D. M., Hempel, A. M., Howard, M., \& Buttner, M. J. (2012). Regulation of apical growth and hyphal branching in Streptomyces. Current Opinion in Microbiology, 15, 737-743.

Flärdh, K., \& van Wezel, G. P. (2003). Cell division during growth and development of Streptomyces. In S. G. Pandalai (Ed.), Recent research developments in bacteriology (pp. 71-90). Trivandrum, India: Transworld Research Network.

Fuchino, K., Bagchi, S., Cantlay, S., Sandblad, L., Wu, D., Bergman, J., et al. (2013). Dynamic gradients of an intermediate filament-like cytoskeleton are recruited by a polarity landmark during apical growth. Proceedings of the National Academy of Sciences of the United States of America, 110, E1889-E1897.

Gao, C., Hindra, Mulder, D., Yin, C., \& Elliot, M. A. (2012). Crp is a global regulator of antibiotic production in Streptomyces. mBio, 3, e00407-e00412.

Gebbink, M. F. B. G., Claessen, D., Bouma, B., Dijkhuizen, L., \& Wösten, H. A. B. (2005). Amyloids-A functional coat for microorganisms. Nature Reviews Microbiology, 3, 333-341.

Girard, G., Traag, B. A., Sangal, V., Mascini, N., Hoskisson, P. A., Goodfellow, M., et al. (2013). A novel taxonomic marker that discriminates between morphologically complex actinomycetes. Open Biology, 3, 130073.

Girard, G., Willemse, J., Zhu, H., Claessen, D., Bukarasam, K., Goodfellow, M., et al. (2014). Analysis of novel kitasatosporae reveals significant evolutionary changes in conserved developmental genes between Kitasatospora and Streptomyces. Antonie Van Leeuwenhoek, in press http://dx.doi.org/10.1007/s10482-014-0209-1.

Glazebrook, M. A., Doull, J. L., Stuttard, C., \& Vining, L. C. (1990). Sporulation of Streptomyces venezuelae in submerged cultures. Journal of General Microbiology, 136, 581-588.

Glazebrook, M. A., Vining, L. C., \& White, R. L. (1992). Growth morphology of Streptomyces akiyoshiensis in submerged culture: Influence of $\mathrm{pH}$, inoculum, and nutrients. Canadian Journal of Microbiology, 38, 98-103.

Glover, W. A., Yang, Y., \& Zhang, Y. (2009). Insights into the molecular basis of L-form formation and survival in Escherichia coli. PLoS One, 4, e7316.

Gottelt, M., Kol, S., Gomez-Escribano, J. P., Bibb, M., \& Takano, E. (2010). Deletion of a regulatory gene within the cpk gene cluster reveals novel antibacterial activity in Streptomyces coelicolor A3(2). Microbiology, 156, 2343-2353.

Gramajo, H. C., Takano, E., \& Bibb, M. J. (1993). Stationary-phase production of the antibiotic actinorhodin in Streptomyces coelicolor A3(2) is transcriptionally regulated. Molecular Microbiology, 7, 837-845.

Granozzi, C., Billetta, R., Passantino, R., Sollazzo, M., \& Puglia, A. M. (1990). A breakdown in macromolecular synthesis preceding differentiation in Streptomyces coelicolor A3(2). Journal of General Microbiology, 136, 713-716.

Gray, D. I., Gooday, G. W., \& Prosser, J. I. (1990). Apical hyphal extension in Streptomyces coelicolor A3(2). Journal of General Microbiology, 136, 1077-1084. 
Grund, A. D., \& Ensign, J. C. (1985). Properties of the germination inhibitor of Streptomyces viridochromogenes spores. Journal of General Microbiology, 131, 833-847.

Gubbens, J., Janus, M., Florea, B. I., Overkleeft, H. S., \& van Wezel, G. P. (2012). Identification of glucose kinase-dependent and -independent pathways for carbon control of primary metabolism, development and antibiotic production in Streptomyces coelicolor by quantitative proteomics. Molecular Microbiology, 86, 1490-1507.

Gueiros-Filho, F. J., \& Losick, R. (2002). A widely conserved bacterial cell division protein that promotes assembly of the tubulin-like protein FtsZ. Genes \& Development, 16, $2544-2556$.

Gumpert, J. (1982). Growth characteristics and ultrastructure of protoplast type L-forms from streptomycetes. Zeitschrift für Allgemeine Mikrobiologie, 22, 617-627.

Gumpert, J. (1983). Ultrastructural characterization of core structures and paracrystalline inclusion bodies in L-form cells of streptomycetes. Zeitschrift für Allgemeine Mikrobiologie, $23,625-633$.

Gust, B., Challis, G. L., Fowler, K., Kieser, T., \& Chater, K. F. (2003). PCR-targeted Streptomyces gene replacement identifies a protein domain needed for biosynthesis of the sesquiterpene soil odor geosmin. Proceedings of the National Academy of Sciences of the United States of America, 100, 1541-1546.

Haiser, H. J., Yousef, M. R., \& Elliot, M. A. (2009). Cell wall hydrolases affect germination, vegetative growth, and sporulation in Streptomyces coelicolor. Journal of Bacteriology, 191, 6501-6512.

Hardisson, C., Manzanal, M. B., Salas, J. A., \& Suárez, J. E. (1978). Fine structure, physiology and biochemistry of arthrospore germination in Streptomyces antibioticus. Journal of General Microbiology, 105, 203-214.

Harriott, O. T., \& Bourret, A. (2003). Improving dispersed growth of Frankia using Carbopol. Plant and Soil, 254, 69-74.

Hempel, A. M., Cantlay, S., Molle, V., Wang, S. B., Naldrett, M. J., Parker, J. L., et al. (2012). The Ser/Thr protein kinase AfsK regulates polar growth and hyphal branching in the filamentous bacteria Streptomyces. Proceedings of the National Academy of Sciences of the United States of America, 109, E2371-E2379.

Heydarian, S. M., Ison, A. P., Lilly, M. D., \& Ayazi Shamlou, P. A. (2000). Turbulent breakage of filamentous bacteria in mechanically agitated batch culture. Chemical Engineering Science, 55, 1775-1784.

Heydarian, S. M., Mirjalili, N., \& Ison, A. P. (1999). Effect of shear on morphology and erythromycin production in Saccharopolyspora erythraea fermentations. Bioprocess Engineering, 21, 31-39.

Hille, A., Neu, T. R., Hempel, D. C., \& Horn, H. (2005). Oxygen profiles and biomass distribution in biopellets of Aspergillus niger. Biotechnology and Bioengineering, 92, 614-623.

Hobbs, G., Frazer, C. M., Gardner, D. C. J., Cullum, J. A., \& Oliver, S. G. (1989). Dispersed growth of Streptomyces in liquid culture. Applied Microbiology and Biotechnology, 31, 272-277.

Hodgson, D. A. (2000). Primary metabolism and its control in streptomycetes: A most unusual group of bacteria. Advances in Microbial Physiology, 42, 47-238.

Holmes, N. A., Walshaw, J., Leggett, R. M., Thibessard, A., Dalton, K. A., Gillespie, M. D., et al. (2013). Coiled-coil protein Scy is a key component of a multiprotein assembly controlling polarized growth in Streptomyces. Proceedings of the National Academy of Sciences of the United States of America, 110, E397-E406.

Hopwood, D. A. (2007). Streptomyces in nature and medicine: The antibiotic makers. New York: Oxford University Press, Inc.

Hopwood, D. A., Wright, H. M., Bibb, M. J., \& Cohen, S. N. (1977). Genetic recombination through protoplast fusion in Streptomyces. Nature, 268(5616), 171-174.

Huang, J., Lih, C. J., Pan, K. H., \& Cohen, S. N. (2001). Global analysis of growth phase responsive gene expression and regulation of antibiotic biosynthetic pathways in Streptomyces coelicolor using DNA microarrays. Genes \& Development, 15, 3183-3192. 
Innes, C. M. J., \& Allan, E. J. (2001). Induction, growth and antibiotic production of Streptomyces viridifaciens L-form bacteria. Journal of Applied Microbiology, 90, 301-308.

Jakimowicz, D., \& van Wezel, G. P. (2012). Cell division and DNA segregation in Streptomyces: How to build a septum in the middle of nowhere? Molecular Microbiology, 85, 393-404.

Jiang, H., \& Kendrick, K. E. (2000). Characterization of $s s f R$ and $s s g A$, two genes involved in sporulation of Streptomyces griseus. Journal of Bacteriology, 182, 5521-5529.

Jonsbu, E., McIntyre, M., \& Nielsen, J. (2002). The influence of carbon sources and morphology on nystatin production by Streptomyces noursei. Journal of Biotechnology, 95, 133-144.

Kawamoto, S., \& Ensign, J. C. (1995). Isolation of mutants of Streptomyces griseus that sporulate in nutrient rich media: Cloning of DNA fragments that suppress the mutations. Actinomycetologica, 9, 124-135.

Kawamoto, S., Watanabe, H., Hesketh, A., Ensign, J. C., \& Ochi, K. (1997). Expression analysis of the $\operatorname{sgg} A$ gene product, associated with sporulation and cell division in Streptomyces griseus. Microbiology, 143, 1077-1086.

Kawamoto, S., Watanabe, M., Saito, N., Hesketh, A., Vachalova, K., Matsubara, K., et al. (2001). Molecular and functional analyses of the gene (esh A) encoding the 52-kilodalton protein of Streptomyces coelicolor A3(2) required for antibiotic production. Journal of Bacteriology, 183, 6009-6016.

Kelemen, G. H., \& Buttner, M. J. (1998). Initiation of aerial mycelium formation in Streptomyces. Current Opinion in Microbiology, 1, 656-662.

Kelly, S., Grimm, L. H., Jonas, R., Hempel, D. C., \& Krull, R. (2006). Investigations of the morphogenesis of filamentous microorganisms. Engineering in Life Sciences, 6, 475-480.

Kendrick, K. E., \& Ensign, J. C. (1983). Sporulation of Streptomyces griseus in submerged culture. Journal of Bacteriology, 155, 357-366.

Keijser, B. J., Noens, E. E., Kraal, B., Koerten, H. K., \& van Wezel, G. P. (2003). The Streptomyces coelicolor ssgB gene is required for early stages of sporulation. FEMS Microbiology Letters, 225, 59-67.

Kim, Y. M., \& Kim, J. H. (2004). Formation and dispersion of mycelial pellets of Streptomyces coelicolor A3(2). The Journal of Microbiology, 42, 64-67.

Koebsch, I., Overbeck, J., Piepmeyer, S., Meschke, H., \& Schrempf, H. (2009). A molecular key for building hyphae aggregates: The role of the newly identified Streptomyces protein HyaS. Microbial Biotechnology, 2, 343-360.

Kojima, I., Cheng, Y. R., Mohan, V., \& Demain, A. L. (1995). Carbon source nutrition of rapamycin biosynthesis in Streptomyces hygroscopicus. Journal of Industrial Microbiology, 14, 436-439.

Kossen, N. W. (2000). The morphology of filamentous fungi. Advances in Biochemical Engineering/Biotechnology, 70, 1-33.

Kwak, J., \& Kendrick, K. E. (1996). Bald mutants of Streptomyces griseus that prematurely undergo key events of sporulation. Journal of Bacteriology, 178, 4643-4650.

Kwak, J., McCue, L. A., Trczianka, K., \& Kendrick, K. E. (2001). Identification and characterization of a developmentally regulated protein, EshA, required for sporogenic hyphal branches in Streptomyces griseus. Journal of Bacteriology, 183, 3004-3015.

Large, K. P., Ison, A. P., \& Williams, D. J. (1998). The effect of agitation rate on lipid utilisation and clavulanic acid production in Streptomyces clavuligerus. Journal of Biotechnology, 63, 111-119.

Leaver, M., Dominguez-Cuevas, P., Coxhead, J. M., Daniel, R. A., \& Errington, J. (2009). Life without a wall or division machine in Bacillus subtilis. Nature, 457, 849-853.

Liman, R., Facey, P. D., van Keulen, G., Dyson, P. J., \& Del Sol, R. (2013). A laterally acquired galactose oxidase-like gene is required for aerial development during osmotic stress in Streptomyces coelicolor. PLoS One, 8, e54112.

Liu, G., Chater, K. F., Chandra, G., Niu, G., \& Tan, H. (2013). Molecular regulation of antibiotic biosynthesis in streptomyces. Microbiology and Molecular Biology Reviews, 77, 112-143. 
Liu, G., Xing, M., \& Han, Q. (2005). A population-based morphologically structured model for hyphal growth and product formation in streptomycin fermentation. World Journal of Microbiology and Biotechnology, 21, 1329-1338.

Liu, L., Yang, H., Shin, H. D., Li, J., Du, G., \& Chen, J. (2013). Recent advances in recombinant protein expression by Corynebacterium, Brevibacterium, and Streptomyces: From transcription and translation regulation to secretion pathway selection. Applied Microbiology and Biotechnology, 97, 9597-9608.

Low, H. H., Moncrieffe, M. C., \& Löwe, J. (2004). The crystal structure of ZapA and its modulation of FtsZ polymerisation. Journal of Molecular Biology, 341, 839-852.

Lucero, H. A., \& Kagan, H. M. (2006). Lysyl oxidase: An oxidative enzyme and effector of cell function. Cellular and Molecular Life Sciences, 63, 2304-2316.

Manteca, A., Alvarez, R., Salazar, N., Yagüe, P., \& Sanchez, J. (2008). Mycelium differentiation and antibiotic production in submerged cultures of Streptomyces coelicolor. Applied and Environmental Microbiology, 74, 3877-3886.

Manteca, A., Claessen, D., Lopez-Iglesias, C., \& Sanchez, J. (2007). Aerial hyphae in surface cultures of Streptomyces lividans and Streptomyces coelicolor originate from viable segments surviving an early programmed cell death event. FEMS Microbiology Letters, 274, 118-125.

Manteca, A., Fernandez, M., \& Sanchez, J. (2005). A death round affecting a young compartmentalized mycelium precedes aerial mycelium dismantling in confluent surface cultures of Streptomyces antibioticus. Microbiology, 151, 3689-3697.

Manteca, A., Fernandez, M., \& Sanchez, J. (2006). Cytological and biochemical evidence for an early cell dismantling event in surface cultures of Streptomyces antibioticus. Research in Microbiology, 157, 143-152.

Manteca, A., Mäder, U., Connolly, B. A., \& Sanchez, J. (2006). A proteomic analysis of Streptomyces coelicolor programmed cell death. Proteomics, 6, 6008-6022.

Manteca, A., Sanchez, J., Jung, H. R., Schwämmle, V., \& Jensen, O. N. (2010). Quantitative proteomic analysis of Streptomyces coelicolor development demonstrates that onset of secondary metabolism coincides with hyphae differentiation. Molecular \& Cellular Proteomics, 9, 1423-1436.

Manteca, A., Ye, J., Sanchez, J., \& Jensen, O. N. (2011). Phosphoproteome analysis of Streptomyces development reveals extensive protein phosphorylation accompanying bacterial differentiation. Journal of Proteome Research, 10, 5481-5492.

Martin, S. M., \& Bushell, M. E. (1996). Effect of hyphal micromorphology on bioreactor performance of antibiotic-producing Saccharopolyspora erythraea cultures. Microbiology, 142, 1783-1788.

McCormick, J. R. (2009). Cell division is dispensable but not irrelevant in Streptomyces. Current Opinion in Microbiology, 12, 689-698.

McCormick, J. R., Su, E. P., Driks, A., \& Losick, R. (1994). Growth and viability of Streptomyces coelicolor mutant for the cell division gene ftsZ. Molecular Microbiology, 14, 243-254.

McCrate, O. A., Zhou, X., Reichhardt, C., \& Cegelski, L. (2013). Sum of the parts: Composition and architecture of the bacterial extracellular matrix. Journal of Molecular Biology, $425,4286-4294$.

Mehmood, N., Olmos, E., Marchal, P., Goergen, J. L., \& Delaunay, S. (2010). Relation between pristinamycins production by Streptomyces pristinaespiralis, power dissipation and volumetric gas-liquid mass transfer coefficient, kLa. Process Biochemistry, 45, 1779-1786.

Mercier, R., Kawai, Y., \& Errington, J. (2013). Excess membrane synthesis drives a primitive mode of cell proliferation. Cell, 152, 997-1007.

Merrick, M. J. (1976). A morphological and genetic mapping study of bald colony mutants of Streptomyces coelicolor. Journal of General Microbiology, 96, 299-315.

Metz, B., \& Kossen, N. W. F. (1977). The growth of molds in the form of pellets-A literature review. Biotechnology and Bioengineering, 19, 781-799. 
Meyerhoff, J., Tiller, V., \& Bellgardt, K.-H. (1995). Two mathematical models for the development of a single microbial pellet. Bioprocess Engineering, 12, 305-313.

Mistry, B. V., Del Sol, R., Wright, C., Findlay, K., \& Dyson, P. (2008). FtsW is a dispensable cell division protein required for Z-ring stabilization during sporulation septation in Streptomyces coelicolor. Journal of Bacteriology, 190, 5555-5566.

Naeimpoor, F., \& Mavituna, F. (2000). Metabolic flux analysis in Streptomyces coelicolor under various nutrient limitations. Metabolic Engineering, 2, 140-148.

Nazari, B., Kobayashi, M., Saito, A., Hassaninasab, A., Miyashita, K., \& Fujii, T. (2013). Chitin-induced gene expression in secondary metabolic pathways of Streptomyces coelicolor A3(2) grown in soil. Applied and Environmental Microbiology, 79, 707-713.

Nielsen, J., \& Villadsen, J. (1992). Modelling of microbial kinetics. Chemical Engineering Science, 47, 4225-4270.

Nieminen, L., Webb, S., Smith, M. C. M., \& Hoskisson, P. A. (2013). A flexible mathematical model platform for studying branching networks: Experimentally validated using the model actinomycete, Streptomyces coelicolor. PLoS One, 8, e54316.

Noens, E. E. E., Mersinias, V., Traag, B. A., Smith, C. P., Koerten, H. K., \& van Wezel, G. P. (2005). SsgA-like proteins determine the fate of peptidoglycan during sporulation of Streptomyces coelicolor. Molecular Microbiology, 58, 929-944.

Noens, E. E. E., Mersinias, V., Willemse, J., Traag, B. A., Laing, E., Chater, K. F., et al. (2007). Loss of the controlled localization of growth stage-specific cell-wall synthesis pleiotropically affects developmental gene expression in an $s s g A$ mutant of Streptomyces coelicolor. Molecular Microbiology, 64, 1244-1259.

Nothaft, H., Dresel, D., Willimek, A., Mahr, K., Niederweis, M., \& Titgemeyer, F. (2003). The phosphotransferase system of Streptomyces coelicolor is biased for $\mathrm{N}$-acetylglucosamine metabolism. Journal of Bacteriology, 185, 7019-7023.

Nothaft, H., Rigali, S., Boomsma, B., Swiatek, M., McDowall, K. J., van Wezel, G. P., et al. (2010). The permease gene nagE2 is the key to N-acetylglucosamine sensing and utilization in Streptomyces coelicolor and is subject to multi-level control. Molecular Microbiology, $75,1133-1144$.

O’Cleirigh, C., Casey, J. T., Walsh, P. K., \& O’Shea, D. G. (2005). Morphological engineering of Streptomyces hygroscopicus var. geldanus: Regulation of pellet morphology through manipulation of broth viscosity. Applied Microbiology and Biotechnology, 68, 305-310.

Ohta, N., Park, Y. S., Yahiro, K., \& Okabe, M. (1995). Comparison of neomycin production from Streptomyces fradiae cultivation using soybean oil as the sole carbon source in an air-lift bioreactor and a stirred-tank reactor. Journal of Fermentation and Bioengineering, 79, 443-448.

Olano, C., Méndez, C., \& Salas, J. A. (2009). Antitumor compounds from marine actinomycetes. Marine Drugs, 7, 210-248.

Olmos, E., Mehmood, N., Husein, L. H., Goergen, J. L., Fick, M., \& Delaunay, S. (2013). Effects of bioreactor hydrodynamics on the physiology of Streptomyces. Bioprocess and Biosystems Engineering, 36, 259-272.

Papagianni, M. (2004). Fungal morphology and metabolite production in submerged mycelial processes. Biotechnology Advances, 22, 189-259.

Papagianni, M., Mattey, M., \& Kristiansen, B. (1999). Hyphal vacuolation and fragmentation in batch and fed-batch culture of Aspergillus niger and its relation to citric acid production. Process Biochemistry, 35, 359-366.

Park, Y., Tamura, S., Koike, Y., Toriyama, M., \& Okabe, M. (1997). Mycelial pellet intrastructure visualization and viability prediction in a culture of Streptomyces fradiae using confocal scanning laser microscopy. Journal of Fermentation and Bioengineering, 84, 483-486.

Paton, A. M., \& Innes, C. M. J. (1991). Methods for the establishment of intracellular associations of L-forms with higher plants. Journal of Applied Microbiology, 71, 59-64. 
Paul, G. C., Kent, C. A., \& Thomas, C. R. (1994). Hyphal vocuolation and fragmentation in Penicillium chrysogenum. Biotechnology and Bioengineering, 44, 655-660.

Paul, G. C., \& Thomas, C. R. (1998). Characterisation of mycelial morphology using image analysis. Advances in Biochemical Engineering/Biotechnology, 60, 1-59.

Peterlin, P., Arrigler, V., Kogej, K., Svetina, S., \& Walde, P. (2009). Growth and shape transformations of giant phospholipid vesicles upon interaction with an aqueous oleic acid suspension. Chemistry and Physics of Lipids, 159, 67-76.

Petrus, M. L. C., \& Claessen, D. (2014). Pivotal roles for Streptomyces cell surface polymers in morphological differentiation, attachment and mycelial architecture. Antonie van Leeuwenhoek, 106, 127-139.

Petrus, M. L. C., van Veluw, G. J., Wösten, H. A. B., \& Claessen, D. (2014). Sorting of Streptomyces cell pellets using a complex parametric analyzer and sorter. Journal of Visualized Experiments, 84, e51178.

Pickup, K. M., \& Bushell, M. E. (1995). Non-fragmenting variants of Streptomyces hyphae have enhanced activity of an enzyme (phospho- $N$-acetylmuramyl pentapeptide translocase) in peptidoglycan biosynthesis. Journal of Fermentation and Bioengineering, 79, 247-251.

Piette, A., Derouaux, A., Gerkens, P., Noens, E. E., Mazzucchelli, G., Vion, S., et al. (2005). From dormant to germinating spores of Streptomyces coelicolor A3(2): New perspectives from the crp null mutant. Journal of Proteome Research, 4, 1699-1708.

Pope, M. K., Green, B. D., \& Westpheling, J. (1996). The bld mutants of Streptomyces coelicolor are defective in the regulation of carbon utilization, morphogenesis and cell-cell signalling. Molecular Microbiology, 19, 747-756.

Postma, P. W., Lengeler, J. W., \& Jacobson, G. R. (1993). Phosphoenolpyruvate:carbohydrate phosphotransferase systems of bacteria. Microbiological Reviews, 57, 543-594.

RayChaudhuri, D. (1999). ZipA is a MAP-Tau homolog and is essential for structural integrity of the cytokinetic FtsZ ring during bacterial cell division. The EMBO Journal, 18, 2372-2383.

Reichl, U., King, R., \& Gilles, E. D. (1992). Characterization of pellet morphology during submerged growth of Streptomyces tendae by image analysis. Biotechnology and Bioengineering, 39, 164-170.

Richards, D. M., Hempel, A. M., Flärdh, K., Buttner, M. J., \& Howard, M. (2012). Mechanistic basis of branch-site selection in filamentous bacteria. PLoS Computational Biology, 8, e1002423.

Rigali, S., Nothaft, H., Noens, E. E. E., Schlicht, M., Colson, S., Müller, M., et al. (2006). The sugar phosphotransferase system of Streptomyces coelicolor is regulated by the GntRfamily regulator DasR and links $\mathrm{N}$-acetylglucosamine metabolism to the control of development. Molecular Microbiology, 61, 1237-1251.

Rigali, S., Titgemeyer, F., Barends, S., Mulder, S., Thomae, A. W., Hopwood, D. A., et al. (2008). Feast or famine: The global regulator DasR links nutrient stress to antibiotic production by Streptomyces. EMBO Reports, 9, 670-675.

Rioseras, B., López-García, M. T., Yagüe, P., Sánchez, J., \& Manteca, A. (2013). Mycelium differentiation and development of Streptomyces coelicolor in lab-scale bioreactors: Programmed cell death, differentiation, and lysis are closely linked to undecylprodigiosin and actinorhodin production. Bioresource Technology, 151C, 191-198.

Rocha-Valadez, J. A., Albiter, V., Caro, M. A., Serrano-Carreón, L., \& Galindo, E. (2007). A fermentation system designed to independently evaluate mixing and/or oxygen tension effects in microbial processes: Development, application and performance. Bioprocess and Biosystems Engineering, 30, 115-122.

Romero, D., Aguilar, C., Losick, R., \& Kolter, R. (2010). Amyloid fibers provide structural integrity to Bacillus subtilis biofilms. Proceedings of the National Academy of Sciences of the United States of America, 107, 2230-2234. 
Romero, J., Liras, P., \& Martin, J. F. (1984). Dissociation of cephamycin and clavulanic acid biosynthesis in Streptomyces clavuligerus. Applied Microbiology and Biotechnology, 20, 318-325.

Rosa, J. C., Baptista Neto, A., Hokka, C. O., \& Badino, A. C. (2005). Influence of dissolved oxygen and shear conditions on clavulanic acid production by Streptomyces clavuligerus. Bioprocess and Biosystems Engineering, 27, 99-104.

Roubos, J. A., Krabben, P., de Laat, W. T. A. M., Babuška, R., \& Heijnen, J. J. (2002). Clavulanic acid degradation in Streptomyces clavuligerus fed-batch cultivations. Biotechnology Progress, 18, 451-457.

Roubos, J. A., Krabben, P., Luiten, R. G. M., Verbruggen, H. B., \& Heijnen, J. J. (2001). A quantitative approach to characterizing cell lysis caused by mechanical agitation of Streptomyces clavuligerus. Biotechnology Progress, 17, 336-347.

Rueda, B., Miguélez, E. M., Hardisson, C., \& Manzanal, M. B. (2001a). Changes in glycogen and trehalose content of Streptomyces brasiliensis hyphae during growth in liquid cultures under sporulating and non-sporulating conditions. FEMS Microbiology Letters, 194, 181-185.

Rueda, B., Miguélez, E. M., Hardisson, C., \& Manzanal, M. B. (2001b). Mycelial differentiation and spore formation by Streptomyces brasiliensis in submerged culture. Canadian Journal of Microbiology, 47, 1042-1047.

Saito, A., Fujii, T., \& Miyashita, K. (2003). Distribution and evolution of chitinase genes in Streptomyces species: Involvement of gene-duplication and domain-deletion. Antonie van Leeuwenhoek, 84, 7-15.

Saito, N., Matsubara, K., Watanabe, M., Kato, F., \& Ochi, K. (2003). Genetic and biochemical characterization of EshA, a protein that forms large multimers and affects developmental processes in Streptomyces griseus. The Journal of Biological Chemistry, 278, 5902-5911.

Saito, A., Shinya, T., Miyamoto, K., Yokoyama, T., Kaku, H., Minami, E., et al. (2007). The das $\mathrm{ABC}$ gene cluster, adjacent to dasR, encodes a novel $\mathrm{ABC}$ transporter for the uptake of N, N'-diacetylchitobiose in Streptomyces coelicolor A3(2). Applied and Environmental Microbiology, 73, 3000-3008.

Sánchez, S., Chávez, A., Forero, A., García-Huante, Y., Romero, A., Sánchez, M., et al. (2010). Carbon source regulation of antibiotic production. The Journal of Antibiotics, $63,442-459$.

Sarrà, M., Casas, C., Poch, M., \& Gòdia, F. (1999). A simple structured model for continuous production of a hybrid antibiotic by Streptomyces lividans pellets in a fluidized-bed bioreactor. Applied Biochemistry and Biotechnology, 80, 39-50.

Savage, G. M., \& Brook, M. J. (1946). The fragmentation of the mycelium of Penicillium notatum and Penicillium chrysogenum by a high-speed blender and the evaluation of blended seed. Journal of Bacteriology, 52, 385-391.

Scher, K., Römling, U., \& Yaron, S. (2005). Effect of heat, acidification, and chlorination on Salmonella enterica serovar typhimurium cells in a biofilm formed at the air-liquid interface. Applied and Environmental Microbiology, 71, 1163-1168.

Schlösser, A., Jantos, J., Hackmann, K., \& Schrempf, H. (1999). Characterization of the binding protein-dependent cellobiose and cellotriose transport system of the cellulose degrader Streptomyces reticuli. Applied and Environmental Microbiology, 65, 2636-2643.

Scholtmeijer, K., de Vocht, M. L., Rink, R., Robillard, G. T., \& Wösten, H. A. B. (2009). Assembly of the fungal SC3 hydrophobin into functional amyloid fibrils depends on its concentration and is promoted by cell wall polysaccharides. The Journal of Biological Chemistry, 284, 26309-26314.

Schrader, K. K., \& Blevins, W. T. (2001). Effects of carbon source, phosphorus concentration, and several micronutrients on biomass and geosmin production by Streptomyces halstedii. Journal of Industrial Microbiology and Biotechnology, 26, 241-247. 
Schumacher, M. A., Karamooz, E., Zikova, A., Trantirek, L., \& Lukes, J. (2006). Crystal structures of T. brucei MRP1/MRP2 guide-RNA binding complex reveal RNA matchmaking mechanism. Cell, 126, 701-711.

Schwedock, J., McCormick, J. R., Angert, E. R., Nodwell, J. R., \& Losick, R. (1997). Assembly of the cell division protein FtsZ into ladder-like structures in the aerial hyphae of Streptomyces coelicolor. Molecular Microbiology, 25, 847-858.

Seo, J. W., Ohnishi, Y., Hirata, A., \& Horinouchi, S. (2002). ATP-binding cassette transport system involved in regulation of morphological differentiation in response to glucose in Streptomyces griseus. Journal of Bacteriology, 184, 91-103.

Shioya, S., Morikawa, M., Kajihara, Y., \& Shimizu, H. (1999). Optimization of agitation and aeration conditions for maximum virginiamycin production. Applied Microbiology and Biotechnology, 51, 164-169.

Smits, W. K., Kuipers, O. P., \& Veening, J. W. (2006). Phenotypic variation in bacteria: The role of feedback regulation. Nature Reviews Microbiology, 4, 259-271.

Stocks, S. M., \& Thomas, C. R. (2001). Strength of mid-logarithmic and stationary phase Saccharopolyspora erythraea hyphae during a batch fermentation in defined nitrate-limited medium. Biotechnology and Bioengineering, 73, 370-378.

Swiatek, M. A., Tenconi, E., Rigali, S., \& van Wezel, G. P. (2012). Functional analysis of the N-acetylglucosamine metabolic genes of Streptomyces coelicolor and role in control of development and antibiotic production. Journal of Bacteriology, 194, 1136-1144.

Takano, E., Gramajo, H. C., Strauch, E., Andres, N., White, J., \& Bibb, M. J. (1992). Transcriptional regulation of the redD transcriptional activator gene accounts for growthphase-dependent production of the antibiotic undecylprodigiosin in Streptomyces coelicolor A3(2). Molecular Microbiology, 6, 2797-2804.

Tamura, S., Park, Y., Toriyama, M., \& Okabe, M. (1997). Change of mycelial morphology in tylosin production by batch culture of Streptomyces fradiae under various shear conditions. Journal of Fermentation and Bioengineering, 83, 523-528.

Tenconi, E., Jourdan, S., Motte, P., Virolle, M. J., \& Rigali, S. (2012). Extracellular sugar phosphates are assimilated by Streptomyces in a PhoP-dependent manner. Antonie van Leeuwenhoek, 102, 425-433.

Thomaides, H. B., Freeman, M., El Karoui, M., \& Errington, J. (2001). Division site selection protein DivIVA of Bacillus subtilis has a second distinct function in chromosome segregation during sporulation. Genes \& Development, 15, 1662-1673.

Titgemeyer, F., Walkenhorst, J., Reizer, J., Stuiver, M. H., Cui, X., \& Saier, M. H. J. (1995). Identification and characterization of phosphoenolpyruvate:fructose phosphotransferase systems in three Streptomyces species. Microbiology, 141, 51-58.

Tokiwa, Y., \& Calabia, B. P. (2004). Degradation of microbial polyesters. Biotechnology Letters, 26, 1181-1189.

Tough, A. J., \& Prosser, J. I. (1996). Experimental verification of a mathematical model for pelleted growth of Streptomyces coelicolor A3(2) in submerged batch culture. Microbiology, 142, 639-648.

Traag, B. A., \& van Wezel, G. P. (2008). The SsgA-like proteins in actinomycetes: Small proteins up to a big task. Antonie Van Leeuwenhoek, 94, 85-97.

Ueda, K., Endo, K., Takano, H., Nishimoto, M., Kido, Y., Tomaru, Y., et al. (2000). Carbon-source-dependent transcriptional control involved in the initiation of cellular differentiation in Streptomyces griseus. Antonie van Leeuwenhoek, 78, 263-268.

van't Riet, K., \& Tramper, J. (1991). Basic bioreactor design. New York: Marcel Dekker, Inc. van Veluw, G. J., Petrus, M. L. C., Gubbens, J., de Graaf, R., de Jong, I. P., van Wezel, G. P., et al. (2012). Analysis of two distinct mycelial populations in liquid-grown Streptomyces cultures using a flow cytometry-based proteomics approach. Applied Microbiology and Biotechnology, 96, 1301-1312.

van Wezel, G. P., Krabben, P., Traag, B. A., Keijser, B. J. F., Kerste, R., Vijgenboom, E., et al. (2006). Unlocking Streptomyces spp. for use as sustainable industrial production 
platforms by morphological engineering. Applied and Environmental Microbiology, 72, 5283-5288.

van Wezel, G. P., \& McDowall, K. J. (2011). The regulation of the secondary metabolism of Streptomyces: New links and experimental advances. Natural Product Reports, 28, 1311-1333.

van Wezel, G. P., McKenzie, N. L., \& Nodwell, J. R. (2009). Chapter 5. Applying the genetics of secondary metabolism in model actinomycetes to the discovery of new antibiotics. Methods in Enzymology, 458, 117-141.

van Wezel, G. P., van der Meulen, J., Kawamoto, S., Luiten, R. G., Koerten, H. K., \& Kraal, B. (2000). ssgA is essential for sporulation of Streptomyces coelicolor A3(2) and affects hyphal development by stimulating septum formation. Journal of Bacteriology, 182, 5653-5662.

van Wezel, G. P., White, J., Hoogvliet, G., \& Bibb, M. J. (2000). Application of redD, the transcriptional activator gene of the undecylprodigiosin biosynthetic pathway, as a reporter for transcriptional activity in Streptomyces coelicolor A3(2) and Streptomyces lividans. Journal of Molecular Microbiology and Biotechnology, 2, 551-556.

Vecht-Lifshitz, S. E., Magdassi, S., \& Braun, S. (1989). Effects of surface active agents on pellet formation in submerged fermentations of Streptomyces tendae. Journal of Dispersion Science and Technology, 10, 265-275.

Vecht-Lifshitz, S. E., Magdassi, S., \& Braun, S. (1990). Pellet formation and cellular aggregation in Streptomyces tendae. Biotechnology and Bioengineering, 35, 890-896.

Vlamakis, H., Chai, Y., Beauregard, P., Losick, R., \& Kolter, R. (2013). Sticking together: Building a biofilm the Bacillus subtilis way. Nature Reviews Microbiology, 11, 157-168.

Vrancken, K., \& Anné, J. (2009). Secretory production of recombinant proteins by Streptomyces. Future Microbiology, 4, 181-188.

Walker, R., Ferguson, C. M. J., Booth, N. A., \& Allan, E. J. (2002). The symbiosis of Bacillus subtilis L-forms with Chinese cabbage seedlings inhibits conidial germination of Botrytis cinerea. Letters in Applied Microbiology, 34, 42-45.

Wang, C. M., \& Cane, D. E. (2008). Biochemistry and molecular genetics of the biosynthesis of the earthy odorant methylisoborneol in Streptomyces coelicolor. Journal of the American Chemical Society, 130, 8908-8909.

Wardell, J. N., Stocks, S. M., Thomas, C. R., \& Bushell, M. E. (2002). Decreasing the hyphal branching rate of Saccharopolyspora erythraea NRRL 2338 leads to increased resistance to breakage and increased antibiotic production. Biotechnology and Bioengineering, 78, 141-146.

Wargenau, A., Fleißner, A., Bolten, C. J., Rohde, M., Kampen, I., \& Kwade, A. (2011). On the origin of the electrostatic surface potential of Aspergillus niger spores in acidic environments. Research in Microbiology, 162, 1011-1017.

Wargenau, A., Kampen, I., \& Kwade, A. (2013). Linking aggregation of Aspergillus niger spores to surface electrostatics: A theoretical approach. Biointerphases, 8, 7.

Waterhouse, R. N., Buhariwalla, H., Bourn, D., Rattray, E. J., \& Glover, L. A. (1996). CCD detection of lux-marked Pseudomonas syringae pv. phaseolicola L-forms associated with Chinese cabbage and the resulting disease protection against Xanthomonas campestris. Letters in Applied Microbiology, 22, 262-266.

White, A. P., Gibson, D. L., Collinson, S. K., Banser, P. A., \& Kay, W. W. (2003). Extracellular polysaccharides associated with thin aggregative fimbriae of Salmonella enterica serovar enteritidis. Journal of Bacteriology, 185, 5398-5407.

Wildermuth, H. (1970). Development and organization of the aerial mycelium in Streptomyces coelicolor. Journal of General Microbiology, 60, 43-50.

Wilking, J. N., Zaburdaev, V., De Volder, M., Losick, R., Brenner, M. P., \& Weitz, D. A. (2013). Liquid transport facilitated by channels in Bacillus subtilis biofilms. Proceedings of the National Academy of Sciences of the United States of America, 110, 848-852. 
Willemse, J., Borst, J. W., de Waal, E., Bisseling, T., \& van Wezel, G. P. (2011). Positive control of cell division: FtsZ is recruited by $\mathrm{SsgB}$ during sporulation of Streptomyces. Genes \& Development, 25, 89-99.

Willemse, J., Ruban-Ośmialowska, B., Widdick, D., Celler, K., Hutchings, M. I., van Wezel, G. P., et al. (2012). Dynamic localization of Tat protein transport machinery components in Streptomyces coelicolor. Journal of Bacteriology, 194, 6272-6281.

Wimpenny, J., Manz, W., \& Szewzyk, U. (2000). Heterogeneity in biofilms. FEMS Microbiology Reviews, 24, 661-671.

Winter, N., Triccas, J. A., Rivoire, B., Pessolani, M. C., Eiglmeier, K., Lim, E. M., et al. (1995). Characterization of the gene encoding the immunodominant $35 \mathrm{kDa}$ protein of Mycobacterium leprae. Molecular Microbiology, 16, 865-876.

Wolánski, M., Wali, R., Tilley, E., Jakimowicz, D., Zakrzewska-Czerwinska, J., \& Herron, P. (2011). Replisome trafficking in growing vegetative hyphae of Streptomyces coelicolor A3(2). Journal of Bacteriology, 193, 1273-1275.

Wösten, H. A. B. (2001). Hydrophobins: Multipurpose proteins. Annual Review of Microbiology, 55, 625-646.

Wösten, H. A. B., \& Willey, J. M. (2000). Surface-active proteins enable microbial aerial hyphae to grow into the air. Microbiolog $\gamma, 146,767-773$.

Wu, L. J., \& Errington, J. (2012). Nucleoid occlusion and bacterial cell division. Nature Reviews Microbiology, 10, 8-12.

Wucherpfennig, T., Kiep, K. A., Driouch, H., Wittmann, C., \& Krull, R. (2010). Morphology and rheology in filamentous cultivations. Advances in Applied Microbiology, 72, 89-136.

Xu, H., Chater, K. F., Deng, Z., \& Tao, M. (2008). A cellulose synthase-like protein involved in hyphal tip growth and morphological differentiation in Streptomyces. Journal of Bacteriology, 190, 4971-4978.

Xu, Q., Traag, B. A., Willemse, J., McMullan, D., Miller, M. D., Elsliger, M. A., et al. (2009). Structural and functional characterizations of SsgB, a conserved activator of developmental cell division in morphologically complex actinomycetes. The Journal of Biological Chemistry, 284, 25268-25279.

Yagüe, P., Rodríguez-García, A., López-García, M. T., Rioseras, B., Martin, J. F., Sánchez, J., et al. (2014). Transcriptomic analysis of liquid non-sporulating Streptomyces coelicolor cultures demonstrates the existence of a complex differentiation comparable to that occurring in solid sporulating cultures. PLoS One, 9, e86296.

Yamazaki, H., Ohnishi, Y., \& Horinouchi, S. (2003). Transcriptional switch on of $s s g A$ by A-factor, which is essential for spore septum formation in Streptomyces griseus. Journal of Bacteriology, 185, 1273-1283.

Yang, H., King, R., Reichl, U., \& Gilles, E. D. (1992). Mathematical model for apical growth, septation, and branching of mycelial microorganisms. Biotechnology and Bioengineering, 39, 49-58.

Yegneswaran, P. K., Gray, M. R., \& Thompson, B. G. (1991). Effect of dissolved oxygen control on growth and antibiotic production in Streptomyces clavuligerus fermentations. Biotechnology Progress, 7, 246-250.

Yikmis, M., \& Steinbüchel, A. (2012). Historical and recent achievements in the field of microbial degradation of natural and synthetic rubber. Applied and Environmental Microbiology, 78, 4543-4551.

Yin, P., Wang, Y. H., Zhang, S. L., Chu, J., Zhuang, Y. P., Chen, N., et al. (2008). Effect of mycelial morphology on bioreactor performance and avermectin production of Streptomyces avermitilis in submerged cultivations. Journal of the Chinese Institute of Chemical Engineers, 39, 609-615.

Zogaj, X., Bokranz, W., Nimtz, M., \& Römling, U. (2003). Production of cellulose and curli fimbriae by members of the family Enterobacteriaceae isolated from the human gastrointestinal tract. Infection and Immunity, 71, 4151-4158. 